\title{
ESOP Fables: \\ The Impact of Employee Stock Ownership Plans on Labor Disputes
}

by

\author{
Peter Cramton, Hamid Mehran, and Joseph Tracy*
}

September 2005

\begin{abstract}
By the early 1990s employee stock ownership plans (ESOPs) had become more prevalent in unionized firms than in nonunionized firms. However, little research has been devoted to examining the implications of ESOPs for collective bargaining. Ben-Ner and Jun (1996) model ESOPs as a buyout option for the union. The ownership share of the typical union ESOP, though, is significantly below $50 \%$. In this paper, we extend the signaling model of Cramton and Tracy (1992) to allow partial ownership stakes by the union. We demonstrate that ESOPs create incentives for unions to become weaker bargainers. As a result, the model predicts that ESOPs will lead to a reduction in the fraction of labor disputes that involve a strike. We examine these predictions using U.S. bargaining data from 1970-1995. The data suggest that ESOPs do increase the efficiency of labor negotiations by reducing dispute rates and shifting the composition of disputes from more costly strikes. Consistent with improved bargaining efficiency, we find that the announcement of a union ESOP leads to a $50 \%$ larger stock market reaction as compared to the announcement of a nonunion ESOP.
\end{abstract}

\footnotetext{
* University of Maryland and Federal Reserve Bank of New York. The views expressed in the paper are those of the authors and are not necessarily reflective of views at the Federal Reserve Bank of New York or the Federal Reserve System. We would like to thank Saeyoung Chang, David Mayers, Susan Chaplinsky, Greg Niehaus and Douglas Shackelford for providing us with data. We benefited from the helpful discussion with Anup Agrawal, Karen Edlunds, the industry insights of Dianne Eberlein, Mark Ublehart, Linda Fisher, Judy Lindquist, Allen Steinberg, and Shelli Greenslade (Hewitt Associates), Elyse Bluth (Duff \& Phelps), David Powell (Groom Law Group, Chartered), Michael Keeling (the ESOP association), and Cory Rosen (National Center for Employee Ownership). In addition, we benefited from the comments received at SOLE and University of Wisconsin. An earlier version of this paper was presented at the meetings of Financial Management Association, the Association of the Financial Economists, and the New York University Law School.
} 
The growth in Employee Stock Ownership Plans (ESOPs) in the 1980s fostered a considerable literature into the reasons for their adoption and their impacts on the adopting firm. ESOPs are "qualified pension” plans that were given explicit recognition and tax incentives by the Employee Retirement Incomes Security Act of 1974 (ERISA). In 1980, 4,925 ESOP plans existed covering approximately 5.3 million workers. By 1995, the number of plans had increased to 9,232 with coverage expanding to 7.2 million workers. ${ }^{1}$ Beginning in 1988, it is possible to identify ESOPs that are established as a part of a collective bargaining agreement. As of 1991, union ESOPs covered 1.1 million workers, 6.6\% of all private sector workers covered by collective bargaining agreements. In the same year, nonunion ESOPs covered 5.5 million workers, $6.4 \%$ of all private sector nonunion workers. ${ }^{2}$ That is, by the early 1990 s ESOPs had become relatively more prevalent in unionized than in nonunionized firms.

Despite the relative prevalence of ESOPs in unionized firms, there has been very little research on the likely impact of ESOPs on collective bargaining. Ben-Ner and Jun (1996) develop a screening model of bargaining that allows the union to use an ESOP to buy a majority equity stake in the firm. In their model, the union's initial offer to the firm during a contract negotiation consists of a wage demand and a buyout price. High valuation firms accept the wage demand with no labor dispute, low valuation firms accept the buyout price again with no labor dispute, and labor disputes screen the remaining intermediate firm types. The buyout option lowers the overall dispute rate and dispute duration by providing the union with an additional screening device.

While including ESOPs as a buyout option in a screening model is an interesting theoretical extension, this option is rarely exercised in practice. Figure 1 shows the distribution of ESOP ownership shares in our data of unionized ESOPs. Less than three percent of unionized ESOPs involve a controlling interest in the firm. ${ }^{3}$ The ownership share for the typical union ESOP is substantially below $50 \%$.

In this paper, we examine the impact of ESOPs on the collective bargaining process when the union has a noncontrolling ownership interest in the firm. This conforms to nearly all union ESOPs observed in the data. Rather than focusing on the adoption of an ESOP as a bargaining

\footnotetext{
${ }^{1}$ See DOL (1999).

${ }^{2}$ We thank Doug Kruse for tabulating the number of participants in collectively bargained ESOPs from the IRS Form 5500 data.
} 
outcome, we focus instead on the effect that an existing ESOP has on current contract negotiations. We do this by extending the signaling model of Cramton and Tracy (1992) to allow the union members to hold an equity stake in the firm. The ESOP causes the union to internalize to a degree the costs to the firm associated with labor disputes. As the union's equity stake grows, we show that the union is less likely to select the strike threat and that the firm is more likely to accept the union's initial wage offer. ESOPs, then, are predicted to both lower dispute incidence and to shift the composition of disputes from strikes towards holdouts. ${ }^{4}$

We test these predictions using a sample of U.S. contract negotiations. This testing is made difficult by the fact that the Bureau of Labor Statistics (BLS) discontinued collecting data on union contract negotiations in 1995. As a result, for most of the bargaining units in our data that adopted an ESOP we have only a couple of contract negotiations following the establishment of the ESOP. With this data limitation in mind, the data indicate a decline in both the incidence of labor disputes and strikes following the adoption of an ESOP. Unionized firms that set up an ESOP appear to have had on average more contentious negotiations with their unions prior to the establishment of the ESOP. This is evidenced by a higher fraction of labor disputes that take the form of a strike. Following the adoption of the ESOP, these firms experience a reduction in the fraction of labor disputes that take the form of a strike. This shift in the composition of disputes is due to the firms that set up a large versus a small ESOP. The data are suggestive, then, that ESOPs do alter the relative attractiveness to the union of the strike and the holdout threat.

The signaling model predicts that ESOPs should improve the efficiency of collective bargaining by reducing the incidence of costly strikes. This improved bargaining efficiency creates value for the firm's shareholders over and above any of the traditional arguments for why ESOPs should lead to higher profitability. This suggests that the announcement of a union ESOP should generate a larger stock market reaction than for the announcement of a non-union ESOP. We test this prediction by conducting an event study of ESOP adoptions. We find that the announcement of a union ESOP leads to a differentially larger stock market reaction a compared

\footnotetext{
${ }^{3}$ The best known example of an ESOP used to give unions a controlling interest in a company was the union buyout of United Airlines in 1993. Cott and Stuart (1995) provide a useful summary of this buyout.

${ }^{4}$ Holdouts are labor disputes in which the union agrees to work under the terms of the expired labor agreement while negotiations continue. In a holdout, the union puts pressure on the firm using a variety of tactics such as "work-to-rule."
} 
to the announcement of a non-union ESOP.

The paper is organized as follows. In the next section we describe important features of ESOP pension plans. In section 3, we show how ESOPs can be added to a signaling model of labor contract negotiations. We discuss the data and present our findings in section 4 . We conduct in section 5 an event study of the announcement of a new ESOP to explore the implications of ESOPs for the firm's shareholders. The final section contains thoughts for future work.

\section{A primer on ESOPs}

ESOPs were formally sanctioned in 1974 as a type of retirement plan under ERISA. A firm that wants to set up an ESOP establishes a trust fund in which to make contributions. These contributions are allocated to individual worker accounts held by the trust. Allocation formulas vary in practice but are based on factors such as the worker's level of compensation and years of service. Vesting of assets allocated to worker accounts takes one of two forms: no vesting for the first five years, followed by $100 \%$ vesting; or $20 \%$ vesting after three years, and $20 \%$ per year for the next four years. The nondiscrimination requirement stipulates that "highly compensated" employees cannot account for more than $30 \%$ of participants in the ESOP. ${ }^{5}$

An important feature of ESOPs for understanding their incentive effects for collective bargaining is that at least fifty percent of the ESOP's assets must be invested in the employer's securities. While other deferred compensation plans may in fact hold significant amounts of employer securities, they are not compelled to do so. Workers with 10 years of plan participation can begin to diversify their ESOP account when they reach age $55 .^{6}$ This diversification option continues until the worker is age 60, when he/she is given a one-time option to diversify up to $50 \%$ of his/her account. ${ }^{7}$ The employee receives the vested assets in his/her account at the end of the employment relationship with the firm. ${ }^{8}$

Shares in an ESOP are legally owned by the ESOP trust. The control rights to these shares reside in the trustee of the plan, who is typically appointed by management. The trustee of

\footnotetext{
${ }^{5}$ Qualified plans must meet nondiscrimination tests regarding (a) coverage and (b) nondiscrimination in plans features. Each of these tests can be met through a variety of tests. Plans covering collectively bargained employees are effectively exempted from these rules.

${ }^{6}$ See Oringer (2001).

${ }^{7}$ This requirement applies to ESOP shares allocated to worker accounts after December 31, 1986.

${ }^{8}$ See http://www.esopassociation.org/whatis/howdo.html
} 
the ESOP votes all nonallocated shares. In public companies, the plan participants must be allowed to vote their shares on "voting issues." ${ }^{9}$ Fiduciary decisions, for example the consideration of a tender offer, need not be passed through to the participants. However, the ESOP can be set up so that this authority is given to the plan participants for decisions on allocated shares. Most public companies do structure their ESOPs in this manner (Rosen, Snyder, and Young 1993).

Motives for adopting an ESOP have been explored in the literature. First, Delaware law makes ESOPs a potential takeover defense. ${ }^{10}$ A firm incorporated in Delaware must wait three years after it acquires $15 \%$ of the target firm's equity before it can merge with the target, unless it can obtain a waiver by $85 \%$ of the shareholders. In 1989, Polaroid won a decision in Delaware Court that upheld the company decision to issue 14\% of its stock to an ESOP prior to the initiation of a hostile tender offer by Shamrock Holdings. Management may feel that giving voting rights to the union through an ESOP is a way of placing the votes in "friendly" hands (e.g., Chang and Myers 1992 and Chaplinsky and Niehaus 1994). Second, ESOPs were given special tax incentives in order to encourage their adoption. The specifics of these tax benefits, though, are not directly relevant for our purpose. Interested readers can find a detailed discussion in Beatty (1995) and Scholes and Wolfson (1990). Finally, ESOPs may improve worker productivity by giving workers and equity stake in the firm. Considerable effort has been devoted to pinning down the productivity effects of profit-sharing in general, and ESOPs in particular (Kruse 1993, Bell and Kruse 1995, and Kruse and Blasi 1995).

The net impact of ESOPs on a firm's profitability can be assessed by conducting an event study of the announcement effect of a new ESOP. The announcement of a new ESOP on average is viewed in a positive light by investors. Studies have found that the average two day cumulative excess stock return on the day prior to and the day of an ESOP announcement ranges from one to three precent (Gordon and Pound 1990 and Beatty 1995). ${ }^{11}$

\footnotetext{
${ }^{9}$ I.R.C. § 4975(e)(7) (1989).

${ }^{10}$ General Corporation Law SS 203, effective 2 February 1988.

${ }^{11}$ This announcement effect captures more than just the tax benefits of an ESOP since it has been documented that stock prices react positively to ESOP adoption even when there is no tax benefit (and adopting companies are takeover targets). See Sellers, Hagan, and Siegel (1994) for further discussion.
} 


\section{Incorporating ESOPs into a bargaining model}

It is often argued that ESOPs serve to improve worker incentives by giving individual workers ownership in the firm. The difficulty with this argument is that any given worker's performance has only a negligible impact on the firm's profitability. A rational worker, outside of top management, should not alter his/her behavior as a result of an ESOP. However, the impact of even a small ESOP on collective bargaining can be dramatic. This is because collective bargaining avoids the dissipation of incentives that is seen at the individual worker level. As a result, the presence of an ESOP will affect the union's wage demand and its decision to strike.

To assess the impact of an ESOP on collective bargaining we extend the wage bargaining model of Cramton and Tracy (1992). The model assumes one-sided private information in which the union is uncertain about the firm's profitability. The firm credibly signals its profitability through its willingness to postpone agreement. The union decides how best to pressure the firm by selecting the threat, either strike or holdout. Under holdout, the union continues to work under the terms of the expired labor agreement, but at a reduced level of efficiency. In contrast, striking typically involves a substantial disruption of production. We will see that an ESOP impacts not only wages, dispute incidence, and dispute duration, but also the form the dispute takes.

Consider the following stylized labor contract negotiation problem. A union and a firm are bargaining over the wage to be paid during a contract of duration $T$. Let $v$ be the firm's value of the current union labor force working under a contract of duration $T$. It is common knowledge that $v$ is drawn from the distribution $F$ with positive density $f$ on an interval of support $[l, h]$. However, at the outset of the negotiations only the firm knows the realized value of $v$.

Negotiations begin with the union selecting a threat $\theta \in\{H, S\}$, where $H$ indicates the holdout threat and $S$ indicates the strike threat. The union's threat choice remains in effect until a settlement is reached. Absent an ESOP, in the threat $\theta$, the payoff to the union is $x_{\theta}$ and the payoff to the firm is $a_{\theta} v-b_{\theta}$, where $a_{\theta} \in[0,1)$ and $b_{\theta} \geq 0$. The term $1-a_{\theta}$ captures the dispute cost in that threat. Define $c_{\theta}=\left(b_{\theta}-x_{\theta}\right) /\left(1-a_{\theta}\right)$ to be the relative payment difference during the threat $\theta$. Since the total payoff in agreement is $v$ and the total payoff during the threat $\theta$ is $a_{\theta} v-$ $b_{\theta}+x_{\theta}$, the "pie" that the union and firm are bargaining over (the difference between the agreement and the threat payoffs $)$ is $\left(1-a_{\theta}\right) v+b_{\theta}-x_{\theta}=\left(1-a_{\theta}\right)\left(v+c_{\theta}\right)$. We assume that the 
pie is positive for all $v \in[l, h]$, which implies that $c_{\theta}>-l$.

Let $w^{0}$ denote the wage under the expired labor agreement. Since the terms and conditions of the previous labor agreement remain in force during a holdout, the workers continue to be paid $w^{0}$ during the holdout, so $x_{H}=b_{H}=w^{0}$ and $c_{H}=0$. We assume there is some inefficiency during a holdout, $a_{H}<1$.

With an ESOP, the union gets a share $\alpha$ of the profits of the firm. This changes the payoff flows both during the threat and after settlement as shown in Figure 2. The outcome of this bargaining process between the union and the firm denoted by $\langle t, w, \theta\rangle$ consists of the time of the settlement $t$ where $t \in[0, \mathrm{~T}]$, the wage settlement $w$ and the threat selected by the union $\theta$. The union and firm payoffs are calculated as the sum of the threat payoffs and the agreement payoffs, weighted by the fraction of time spent in each state.

Define

$$
D(t)=\frac{1-e^{-r t}}{1-e^{-r T}}
$$

to be the discounted fraction of time spent in dispute if an agreement occurs at time $t$. Then, given the bargaining outcome $\langle t, w, \theta\rangle$, the union's payoff is

$$
U(t, w, \theta)=\left[x_{\theta}+\alpha\left(a_{\theta} v-b_{\theta}\right)\right] D(t)+[w+\alpha(v-w)][1-D(t)]
$$

and the firm's payoff is

$$
V(t, w, \theta)=(1-\alpha)\left(a_{\theta} v-b_{\theta}\right) D(t)+(1-\alpha)(v-w)[1-D(t)]
$$

Notice that the ESOP does not change the firm's incentives. The firm still seeks to maximize its overall profits, despite the fact that a share $\alpha$ of these profits is going to the union. In contrast, the ESOP does fundamentally change the incentives of the union. With an ESOP, the union cares not only about its wage, but also about the firm's profitability, which falls with higher wages and longer and more costly labor disagreements. As a result, the ESOP makes the union a less demanding negotiator. As we will see, the ESOP gives the union an incentive to select a less destructive threat and to demand a lower initial wage demand. 
The bargaining sequence is as follows. Following the union's threat choice the union and the firm alternate making wage offers, with the union assumed to make the initial offer. After a wage offer is made by one side, the other side has two options: (1) make a counteroffer, in which case the bargaining continues, or (2) accept the current offer, in which case the bargaining ends and labor is supplied at the offered wage for the reminder of the contract period. As in Admati and Perry (1987), a bargainer can delay responding to an offer. This assumption leads to the signaling equilibrium in which the firm signals its value through its willingness to delay the agreement. For simplicity, we assume that the minimum time between offers is arbitrarily small.

The equilibrium of this bargaining game takes a simple form. If the wage under the expired labor agreement, $w^{0}$, is sufficiently low (that is, below some indifference level $\tilde{w}$ ) the union decides to select the strike threat; otherwise $\left(w^{0} \geq \tilde{w}\right)$ the union selects the holdout threat. The indifference level wage, $\tilde{w}$, depends on $r, T, F$, the strike and holdout threat payoffs and the ESOP size $\alpha$. A second indifference level, $m \in(l, h)$, determines the firm's response to the union's initial wage offer. If the firm's valuation is higher than this indifference level, $v>m$, the firm accepts the union's initial wage offer and an immediate settlement takes place. Otherwise, the firm rejects the union's initial wage offer and a labor dispute begins. Whether the dispute is a strike or a holdout depends on the union's prior threat choice.

The signaling equilibrium is characterized by three propositions, which are proven in Appendix A.

Proposition 1. Let $\theta$ be the threat chosen by the union. In the limit as the time between offers goes to zero, there is a perfect Bayesian equilibrium with the following form:

- The union makes an immediate offer of $w_{\theta}(m)=x_{\theta}+\frac{1-2 \alpha}{2-2 \alpha}\left(1-a_{\theta}\right)\left(m+c_{\theta}\right)$, where $m\left(c_{\theta}\right) \in(l, h)$ maximizes

$$
(1-2 \alpha)\left(m+c_{\theta}\right)(1-F(m))+\int_{l}^{m}\left(\frac{\left(v+c_{\theta}\right)^{2-2 \alpha}}{\left(m+c_{\theta}\right)^{1-2 \alpha}}-2 \alpha\left(v+c_{\theta}\right)\right) d F(v) .
$$

- The firm accepts the offer if $v \geq m$. Otherwise, if $v<m$ the firm waits until $\left(\frac{v+c_{\theta}}{m+c_{\theta}}\right)^{1-2 \alpha}$ of the contract period remains before offering $w_{\theta}(v)=x_{\theta}+\frac{1-2 \alpha}{2-2 \alpha}\left(1-a_{\theta}\right)\left(v+c_{\theta}\right)$, which is accepted by the union. 
Several observations follow from Proposition 1. First, all wage offers are Rubinstein (1982) full information wage offers. The wage offer consists of the union's payoff in the threat $\theta$ , $x_{\theta}$, plus the fraction $\frac{1-2 \alpha}{2-2 \alpha}$ of the bargaining rents (the avoided loss) based on the firm's profitability, $v$ (or $m$ in the case of the union's initial offer). For bargaining units without an ESOP ( $\alpha=0$ ), the rents are split equally between the union and the firm with the union receiving its share of the rents entirely through the settlement wage. At the other extreme, for bargaining units with a controlling interest in the firm $(\alpha=1 / 2)$, there is no longer any bargaining conflict between the firm and the union. The union receives a "competitive” wage equal to its threat payoff, $x_{\theta}$. However, the union still collects half of the rents, $\mathrm{v}-x_{\theta}$, though it now receives the payment entirely through its equity stake. For intermediate values of $\alpha$, the union receives some of its rents through the wage and some through its equity stake. Second, during a labor dispute the union has every incentive to impose as much inefficiency on the firm as possible. The wage under both threats increases linearly with the degree of inefficiency, but the strength of this incentive diminishes with $\alpha$.

For a given threat $\theta$, we can determine how the dispute incidence and duration respond to changes in the distribution of $v$, changes in the threat payoffs, or to changes in the size of the ESOP. The following proposition says that dispute activity increases with uncertainty. In addition, dispute activity increases when the threat $\theta$ becomes more attractive to the union (i.e., $c_{\theta}$ falls). However, dispute activity decreases with larger ESOPs (as $\alpha$ rises).

Proposition 2. Suppose that $m$ uniquely maximizes (M). Dispute incidence $F(m)$ and dispute duration $D(v) \equiv 1-\left(\frac{v+c_{\theta}}{m+c_{\theta}}\right)^{1-2 \alpha}$ increase with a linear, mean-preserving spread of the distribution of F. Moreover, dispute incidence and duration decrease as $c_{\theta}$ increases and as $\alpha$ increases.

Dispute activity depends on the amount of uncertainty about the firm's private information. Dispute incidence always exceeds one-half, and converges to one-half in the limit 
as uncertainty disappears. ${ }^{12}$ Recall that $c_{\theta}$ measures what the firm pays less what the union receives in the threat $\theta$ scaled by the dispute cost. Proposition 2 yields several testable predictions. For example, if a local union receives strike benefits throughout a strike from its national union (and the costs of the benefits are spread across the national membership), then this lowers $C_{\mathrm{S}}$ which should increase strike incidence and lengthen strike durations. Similarly, if workers on strike qualify for general welfare payments, this also lowers $C_{S}$ and should increase the incidence and duration of strikes.

The intuition for why ESOPs reduce dispute incidence and dispute duration stems from the fact that as $\alpha$ increases the union's preferences become more in line with the firm. A bargaining unit without an ESOP receives rents only through the negotiated wage. Labor disputes are a costly activity that allows the union to raise its wage. A bargaining unit with an ESOP no longer collects its rents entirely through the negotiated wage. Depending on the size of the ESOP, a portion of the union's rents is now collected through its ownership stake in the firm. As the ESOP share $\alpha$ increases, the union collects a higher share of its rents through its equity stake, which dampens the union's incentive to invest in costly labor disputes in order to raise its wage. At $\alpha=1 / 2$, all of the union's rents are collected through its equity stake and there is nothing left to disagree about. Consequently, dispute incidence and duration vanishes to zero.

Our third proposition demonstrates that the union's threat decision depends critically on the current wage under the expired labor agreement, $w^{0}$.

Proposition 3. If $w^{0}<\tilde{w}$, the union selects the strike threat; if $w^{0} \geq \tilde{w}$ the union selects the holdout threat, where

$$
\begin{aligned}
& \tilde{w}=x_{S}+\left(1-a_{S}\right)\left(m_{S}+c_{S}\right)\left(1-F\left(m_{S}\right)\right)-\left(1-a_{H}\right) m_{H}\left(1-F\left(m_{H}\right)\right) \\
& -\frac{\alpha}{1-\alpha}\left(c_{S}\left(1-a_{S}\right) F\left(m_{S}\right)+\left(1-a_{S}\right) \int_{l}^{m_{S}} v d F(v)-\left(1-a_{H}\right) \int_{l}^{m_{H}} v d F(v)\right)
\end{aligned}
$$

and $m_{S}=m\left(c_{S}\right)$ and $m_{H}=m\left(c_{H}\right)$ maximize $(\mathbf{M})$.

\footnotetext{
${ }^{12}$ By dispute incidence we mean the likelihood that either a strike or a holdout takes place. Dispute incidence less than one-half results when there is a fixed cost to initiating a dispute.
} 
The intuition is that the union will select the strike threat if and only if the higher bargaining costs that are associated with a strike are more than made up for by a higher wage. If the current wage under the expired labor agreement is sufficiently high, this is not the case and the union prefers the holdout threat.

Proposition 3 provides a key insight into strike activity. The overall incidence of strikes depends not just on the overall incidence of disputes, but also on the fraction of disputes that involve a strike. As shown earlier, the level of dispute activity depends on the degree of uncertainty and the size of the ESOP. The composition of disputes between strikes and holdouts depends on $w^{0}$, the size of the ESOP, the threat payoffs and the location of the distribution of $v$.

We would like to determine how the size of the ESOP impacts the composition of disputes. An examination of the Rubinstein wage provides some insight:

$$
w_{\theta}(v)=x_{\theta}+\frac{1-2 \alpha}{2-2 \alpha}\left(1-a_{\theta}\right)\left(v+c_{\theta}\right)
$$

We see that as $\alpha$ increases, the wage under both threats falls. However, assuming that the strike threat is much more destructive than the holdout threat $\left(a_{S}<<a_{H}\right)$, then it is the case that as the ESOP share increases the wage under the strike threat is falling much faster than the wage under the holdout threat. A higher ESOP share reduces the relative wage gap between the strike and the holdout threats. Hence, we should expect that an ESOP should increase the relative attractiveness of the holdout threat. The incentive to strike is further reduced when the union factors in the dispute costs. The less destructive threat, holdout, results in lower dispute costs. Thus, our intuition is that we should expect ESOPs to shift the composition of disputes away from strikes.

This intuition is difficult to establish without making further assumptions on the threat payoffs. One useful simplification is

Assumption S. $b_{S}=x_{S}$.

This states that what the firm pays out during a strike is equal to what the union receives 
implying that $c_{S}=0 .{ }^{13}$ In the case of holdout, recall that the firm pays the union the wage from the expired contract, which means $b_{H}=x_{H}=w^{0}$, and $c_{H}=0$. Thus, with Assumption $\mathrm{S}, c_{H}=c_{S}=$ 0 , which implies that the union selects the same cutoff level $m$ under either threat $\left(m=m_{S}=m_{H}\right)$. As a result, the incidence and duration of the dispute is the same under either threat. Since $a_{S}<$ $a_{H}$, it immediately follows that the expected loss from a strike is higher than the expected loss from a holdout. In addition, we can show

Proposition 4. Suppose Assumption $S$ holds and $m$ is the unique maximizer of (M). Then as $\alpha$ increases from $0, \tilde{w}$ falls and the union is more apt to choose the holdout threat. Moreover, if $v$ is uniformly distributed, then for all $\alpha$, the union's threat choice shifts toward holdout as the size of the ESOP grows.

Propositions 1-4 yield a number of predictions about how collective bargaining changes with the introduction of an ESOP. As union's equity grows, we should expect fewer and shorter disputes. Moreover, the union should be less apt to select the more destructive strike threat, and thus strike incidence should be less. To get a sense of the magnitude of these effects, we set the model parameter values to the benchmark levels of Cramton and Tracy (1994). These parameter values were calibrated such that the equilibrium outcome with $\alpha=0$ (no ESOP) fits the descriptive statistics of private-sector collective bargaining in large (more than 1,000 workers) private-sector bargaining units in the U.S. from 1970 to $1989 .{ }^{14}$

Figure 3 shows how dispute incidence changes in the benchmark model with the introduction of an ESOP. Overall dispute incidence declines slowly as the ESOP ownership share increases from 0 to 25 percent. However, there is a substantial change in the form that disputes take, resulting in a large decline in strike incidence. Strike incidence, initially at 11 percent with $\alpha=0$ falls roughly linearly to 0 at $\alpha=0.17$. This decline in strike incidence is the result of the union avoiding the more costly strike threat when the union has an equity interest in

\footnotetext{
${ }^{13}$ Assumption S can hold in a variety of situations. If the firm closes down during a strike and the union workers do not find alternative employment, then the assumption holds. Similarly, if the firm hires replacements at a competitive wage and the striking workers find alternative employment at the competitive wage then the assumption also holds.

${ }^{14}$ Specifically, we assume $v$ is uniform on $1 \pm 0.07, w^{0}$ is uniform on $0.48 \pm 0.05, a_{S}=0.75, a_{H}=0.96, x_{S}$ $=b_{S}=0.35, r=10 \%$, and $T=2.7$ years.
} 
the firm.

Figure 4 shows how the expected loss from disputes declines as the union's ESOP ownership share increases. The expected loss conditional on the strike threat is cut in one-half as $\alpha$ increases from 0 to 0.25 - this is the consequence of mean strike duration dropping from 36 days at $\alpha=0$ to 18 days at $\alpha=0.25$. However, the expected loss from disputes drops by a factor of more than four as $\alpha$ increases from 0 to 0.25 . The faster decline in dispute loss is the result of two sources of reduction as the union's equity interest increases: 1) shorter disputes and 2) the shift away from the more costly strike threat.

The decline in dispute costs with the introduction of an ESOP raises the possibility that both the union and the firm may benefit from the ESOP, all else equal. In our benchmark model, this is not the case. With $\alpha=0$, the union and firm split the pie roughly equally, but as the union's ownership share increases to 20 percent, the split shifts to 60/40 in favor of the union. This suggests that firms would offer ESOPs only in conjunction with some combination of tax breaks and concessions by the union.

To summarize, the benchmark model—calibrated to fit the main features of U.S. collective bargaining — suggests several hypotheses: 1) ESOPs should result in lower strike incidence and strike duration, 2) ESOPs should result in lower expected dispute costs, and 3) ESOPs should be associated with union concessions. The size of the ESOP impact depends on the union's ownership share of the firm. According to the benchmark model, the average impact of introducing an ESOP based on the observed distribution of ESOP shares (see Figure 1) is as follows: dispute incidence falls from 51.8 to 51.6 percent, strike incidence falls from 11.1 to 5.5 percent, and the union's selection of the strike threat falls from 21.4 to 10.7 percent.

\section{ESOP data and empirical findings}

Our primary data source for ESOP information was the National Center for Employee Ownership (NCEO). For each publicly held corporation, we used NCEO data to determine whether an ESOP exists, the date the ESOP was adopted, and the percent of total shares held by the ESOP. We sent surveys to 387 corporations where there was any indication of possible error in the NCEO data. A total of 268 companies responded to the survey, although about a third of responses were not informative since the plan administrators claimed that they did not have information about the specific circumstances surrounding the adoption of their ESOPs. We made 
corrections to the data based on the usable survey responses. In addition, we checked the accuracy of our ESOP data against those reported in Chang and Mayers (1992), Gordon and Pound (1990), and Chaplinsky and Niehaus (1994). Finally, we cross-checked our data with the information provided to the Internal Revenue Service in the Form 5500. ${ }^{15}$ We were unable to check the accuracy of ESOPs that were put into place before 1988 due to the fact that many of these companies were subsequently delisted. Our final ESOP sample for which we have complete data consists of 140 firms.

Our collective bargaining data consists of all major bargaining units followed by the Bureau of Labor Statistics (BLS) from 1970 to $1995 .{ }^{16}$ The BLS compiles settlement, effective, and expiration dates for each round of contract negotiations. Strike beginning and ending dates are from BLS and Bureau of National Affairs data, and consist of compilations from public sources. Each bargaining unit is assigned a unique identification number by the BLS. A total of 1,284 bargaining units and 8,665 negotiations are captured in the data. CUSIP numbers were merged in using the firm name(s) listed by the BLS and data sources on mergers and acquisitions during the sample period.

We merged the sample of ESOPs into our collective bargaining data using the firm's CUSIP number. This merging had to be done with care to take account of any mergers and acquisitions, as well as instances where firms sell-off or acquire divisions that are covered by collective bargaining. ${ }^{17}$ For example, a division of a company with its bargaining units covered by an ESOP may be sold to another company with no ESOP (or, alternatively, the division may go through a management/leverage buy out). ${ }^{18}$ For our analysis, we tracked bargaining units and

\footnotetext{
${ }^{15}$ Every ESOP involving more than 100 participants must file a Form 5500 report with the Internal Revenue Service. Beginning in 1988, the Form 5500 data indicate if the ESOP is part of a collective bargaining unit.

${ }^{16}$ Major bargaining units cover 1,000 or more workers. The BLS stopped collecting bargaining data on major bargaining units in 1995.

${ }^{17}$ If the firm is being acquired then the treatment of its ESOP is similar to a 401(k) plan -- the assets would be moved into a successor plan, usually a 401(k) in the acquirer. That plan might sell the shares if it is a large percentage of the acquirer s stock. Alternatively, the shares could be cashed out and employees could roll them into an IRA or pay taxes and keep the money, or the employees could simply be given the shares.

${ }^{18}$ A company that sells a division has a few options: (a) without affirmative employer action, the affected employees are treated as any terminated employees. The vested employees can then receive distributions pursuant to the plan's general provisions, and unvested employees forfeit their interest. (b)
} 
whether or not they are covered by the original ESOP plan. Tracking firms and divisions is somewhat easier for public corporations. We used Standard \& Poors Compustat and Center for Research in Securities Prices (CRSP) as primary source of data for tracking firms and divisions. For additional background detail, we used Securities Data Corporation data on asset sell-offs for restructuring in the 90s, Moody’s Manuals, 10-Ks filed with the SEC, and Directory of Corporate Affiliates.

The pattern of adoption of ESOPs over time in our data is presented in Table 1. Of the 142 total ESOP plans that we linked to our bargaining data, around 2\% were put into place in the year following the passage of ERISA. In the early to mid-1980s some ESOPs were put into place as part of concession bargaining by the firm. ${ }^{19}$ Adoption rates significantly picked up in 1989 , following the enhancement of some of the ESOP tax incentives and the Polaroid decision.

Overall, ESOPs were adopted by $12 \%$ of the bargaining units in our data. A total of $88 \%$ of contract negotiations involve firms that never adopt an ESOP. For the bargaining units involving firms that adopt an ESOP, the negotiations prior to the adoption date represent $11 \%$ of the total sample, while the negotiations following the adoption date represent only $1 \%$. Restricting attention to the firms adopting ESOPs, 92\% of their negotiations occur prior to the adoption date. The fact that many ESOPs are adopted late in our sample period will make estimating their impact on bargaining more difficult due to the shortage of post-adoption negotiations.

Table 2 gives the distribution of ESOPs across broad industry classifications. The incidence of adoption among unionized firms is not uniform across industry classifications, and

the company could choose to vest all employees, and otherwise treat the employees under (a) above. (c) the employer could retain the funds in the ESOP, and give continuing vesting service for employment with the buyer. Under any of these options, the employer might also facilitate rollovers to the buyer's plan (after liquidating the stock). Alternatively, the seller could implement a "trust-to-trust" transfer to the buyer's plan (again, with or without fully vesting--but usually after vesting). If a trust-to-trust transfer occurs, the buyer can either retain the stock fund (but freeze it) to enable the participants to retain favorable tax treatment (on net unrealized appreciation) upon distribution. However, most employers would prefer to liquidate the stock fund quickly. It should be noted that a partial termination requires full vesting. A partial termination occurs if a significant percentage of a plan's population is terminated as the result of employer action. Over $50 \%$ termination is always a partial termination, under $20 \%$ is never a partial termination and anything between $20 \%$ and $50 \%$ is subject to evaluation based on facts and circumstances.

${ }^{19}$ See Flanagan (1984) for examples. 
is relatively high in Petroleum \& Coal and Transportation Equipment. Bell and Kruse (1995) using Form 5500 data find that the overall incidence of ESOPs was 72.7\% in Communications, 39.2\% in Utilities, 11.3\% in Manufacturing, and 11.7\% in Finance, Insurance, and Real Estate. Bell and Kruse report that the incidence of ESOP adoption is three times higher in "high technology” sectors than for the private sector as a whole.

A simple tabulation of the incidence of strikes and labor disputes by ESOP status is provided in Table 3. In this table we report strike incidence, dispute incidence, and the composition of disputes by ESOP status. The overall incidence of labor disputes in our sample is $49 \%$, while the incidence of strikes is $12 \%$. Only about a quarter of labor disputes involve a strike. Comparing the pre-ESOP outcomes with the post-ESOP outcomes we see that strike incidence falls, dispute incidence rises and the fraction of disputes that involve a strike falls quite dramatically.

We can use the tabulations in Table 3 to calculate a rough estimate of the impact of ESOPs on collective bargaining outcomes. Recall that most of our ESOPs were adopted after 1988. We can see from the pre-1989 and post-1989 breakdown of the sample of negotiations without ESOPs that there were important time trends in collective bargaining outcomes. Both the incidence of strikes and the fraction of disputes involving a strike were declining, while the incidence of labor disputes was rising. For any of the three bargaining outcomes, taking the difference in the post-ESOP and pre-ESOP outcomes and subtracting the difference in the post1989 and pre-1989 outcomes gives a simple estimate of the ESOP effect. These ESOP impacts are provided in the last row of Table 3. The tabulations suggest that the impact of ESOPs line up directionally with the predictions of the model: ESOPs lower strike incidence, lower dispute incidence and lower the fraction of disputes that involve a strike.

The simple difference in difference estimates that are reported in Table 3 provide at best only a rough idea of the likely impact of ESOPs on collective bargaining outcomes. To investigate further the impact of ESOPs on the collective bargaining process, we estimate strike incidence, dispute incidence and dispute composition specifications using conditional logit models. These specifications allow us to control more precisely for cyclical effects on bargaining, changes in bargaining patterns over time, and factors specific to each bargaining unit that impact bargaining outcomes.

All of our logit specifications control for cyclical patterns in bargaining using aggregate, 
industry and local labor market controls. Aggregate cyclical conditions are captured by a set of year effects. These year effects will also control for changes in bargaining trends over time. ${ }^{20}$ Conditions in the industry and state labor markets are proxied by a set of employment residuals. We fit regression models to the BLS quarterly industry and state-level employment series for the period 1970-1995. We allow for quadratic trends, quarterly seasonal effects, and autoregressive error terms.

$$
\begin{gathered}
\ln E_{i t}=\beta_{i 0}+\beta_{i 1} t+\beta_{i 2} t^{2}+\sum_{j=1}^{3} \delta_{i j} Q_{j}+U_{i t} \\
U_{i t}=\phi(L) U_{i t-1}+\varepsilon_{i t},
\end{gathered}
$$

where $\ln E_{i t}$ is $\log$ quarterly employment in industry/state $i$ at time $t ; Q_{j}$ is an indicator variable for the $\mathrm{j}^{\text {th }}$ quarter; $\phi(\mathrm{L})$ is a second-order distributed lag polynomial; and $\varepsilon_{\mathrm{it}}$ is a white noise error term. We measure the tightness in the relevant labor market using the estimated quarterly employment residual, $U_{\mathrm{it}}$. We also include the estimated current employment growth rate $\left(\exists_{\mathrm{i} 1}+2 \exists_{\mathrm{i} 2} \mathrm{t}\right)$ as a measure of longer-term performance in the industry or state.

We take the panel nature of the data into account in the estimation by controlling for bargaining unit fixed effects. For those bargaining units that adopt an ESOP, we include a preand post-adoption indicator in the specification. We measure the impact of ESOPs on bargaining outcomes by taking the difference between the pre- and post-adoption coefficient estimates. This approach does not constrain the bargaining units that adopt ESOPs to have negotiated like the non-adopting bargaining units prior to putting the ESOP in place.

The overall impact of ESOPs on strikes is given in specification (1) of Table 4. The data indicate that bargaining units that are associated with firms that adopt ESOPs were 5.9 percentage points less likely to experience a labor dispute in the pre-adoption period relative to bargaining units at firms that never adopt an ESOP. Following the adoption of an ESOP, the strike incidence for adopting bargaining units declines by another 8 percentage points. Similarly, specification (2) suggests that ESOP bargaining units experienced on average a 6.7 percentage point lower dispute rate prior to the adoption of the ESOP. Following the establishment of the

\footnotetext{
${ }^{20}$ For example, strike incidence has declined by roughly 50\% over this twenty-five year period.
} 
ESOP, these same bargaining units experienced an additional 5.6 percentage point decline in their dispute rate. Finally, as indicated in specification (3), ESOP bargaining units were more likely to select the strike threat during contract negotiations that were conducted prior to the ESOP. Following the establishment of the ESOP, the fraction of disputes that involved a strike declined by 18.1 percentage points. These ESOP impacts are all larger than the naïve estimates reported in Table 3. However, the data is unable to precisely measure any of these three impacts. The evidence, though, is suggestive that ESOPs may alter the relative attractiveness of the union's two threat choices inducing the union to substitute away from strikes and towards holdouts.

Table 5 compares the average impact of ESOP adoption based on the theoretical benchmark model from section 3 with the empirical impact estimated from Table 4. Despite being imprecisely measured, the estimated impact of ESOPs on strike incidence and dispute composition is roughly consistent with the theoretical model.

The analysis so far has examined the overall impact of ESOPs on collective bargaining outcomes regardless of the size of the ESOP. To investigate whether the effects of ESOPs differ by size, we classify ESOPs into large and small size categories based on whether the ESOP owns at least $8.5 \%$ of the firm's equity. This threshold is the median ESOP size in our sample of union ESOPs.

Table 6 reexamines the impact of ESOPs on collective bargaining outcomes but allows for differential effects across the two size categories. The reduction in strike and dispute rates following the adoption of an ESOP is more pronounced for small ESOPs. In contrast, the impact of ESOPs on the composition of labor disputes is driven entirely by large ESOPs. The effect of ESOP size on the composition of labor disputes is given in specification (3) of Table 6. We saw in Table 4 that bargaining units that adopt an ESOP experienced on average a higher fraction of disputes involving a strike in the pre-adoption period. We see in specification (3) of Table 6 that this is true for both small and large ESOPs. Following the adoption of the ESOP, the bargaining units with a large ESOP experienced on average a 33.6 percentage point decline in the fraction of their disputes that took the form of a strike. This is a large swing in the composition of disputes. ${ }^{21}$ Again, the paucity of post-ESOP contract negotiations makes it difficult to pin down the post-adoption dispute composition marginal effect. The only finding that is statistically

\footnotetext{
${ }^{21}$ Bargaining units that adopt a large ESOP have a pre-adoption dispute rate of $35.3 \%$.
} 
significant is the impact of large ESOPs on the incidence of strikes. The point estimate, though, suggests that larger ESOPs may substantially alter the relative attractiveness of the strike versus the holdout threat.

\section{Shareholder and Labor Wealth Effects}

In this section, we analyze the shareholder wealth associated with the announcement of an ESOP adoption. While the market reaction to an announcement of a new ESOP has been documented in the literature, we provide new evidence on the announcement gains/losses disaggregated by the collective bargaining status of the firm. If ESOPs improve the efficiency of contract negotiations and if these efficiency gains are shared between the union and the firm, then we would expect to see these gains to the shareholders capitalized into the announcement effect of a union ESOP. We measure these announcement effects using an event-time methodology as described in MacKinaly (1997). We calculate cumulative abnormal returns (CAR) over three intervals around the announcement date of ESOP. We also normalize the gain or loss by the number of employees to find out the average gain/loss to each worker. ${ }^{22}$

Table 7 provides descriptive statistics on the firms in our overall (union and non-union) ESOP sample where we know the exact date of the ESOP adoption. ${ }^{23}$ We report information on firm size (measured by the book value of assets and employment), growth opportunities (measure by market to book ratio), and the size of the ESOP as a percentage of shares outstanding. Our sample of ESOP firms on average has nearly $\$ 5.0$ billion in assets. Unionized firms, with an average size of $\$ 10.6$ billion are about 3.4 times larger than the non-unionized firms. An average firm in our ESOP sample has about 21,000 employees. The unionized firms have workforces that are double the size of the non-unionized firms. Firms that adopt an ESOP have a mean (median) market to book of 1.3 (1.2), indicating growth prospects. Unionized firms have a slightly higher market to book than non-unionized firms. ESOPs on average have 11.6\%

\footnotetext{
${ }^{22}$ We take the number of employees for the year of ESOP adoption for each firm as reported by the Standard \& Poor's Compustat database. It should be noted that the results reported here do not change if we choose the number of employees in the year before the year of ESOP adoption. The daily returns used in our study are collected from the Center for Research in Security Prices.
} 
of the firm's shares outstanding, with a median equity stake of 8.0\%. Appendix B provides information on the name of the company, the year of ESOP adoption and percentage shares outstanding in the plan for our sample of union ESOPs.

Table 8 reports the event study results. We report CARs for three event windows $(-5,5)$, $(-5,1)$, and $(-2,1)$, where $t=-1$ is the ESOP announcement date, and $t=0$ is the date the announcement is reported in the press. For two of the event windows, we include the five days prior to the press release to capture any leakage of the news to the markets, although little is reported in the literature as to when the firm, if at all, shares the information with its employees about the ESOP. CARs for the overall sample of firms are positive and statistically significant over each of the three intervals. The eleven-day CAR $(-5,5)$ and the seven-day CAR $(-5,1)$ are $1.6 \%$ and $1.5 \%$ respectively, while the four-day CAR $(-2,1)$ is $1.3 \%$.

Since our sample is different than those in other studies, we compare the announcement returns with findings in three other papers. Our calculated four-day return of $1.3 \%$, is a bit higher than that of Beatty (1995) and Chang and Mayers (1992), but is much lower than Chang (1990) as reported below. These studies differ because of the type of ESOPs included in the sample. Beatty points out that Chang's reported excess return of $3.7 \%$ would be reduced to $1.6 \%$ if the 35 leveraged buyout ESOPs were excluded from his sample. Thus, our announcement return is roughly comparable to other studies.

\begin{tabular}{llll} 
Study & Sample Size & Sample Period & CARs \\
\hline Beatty (1995) & 122 & $1976-1989$ & $1.0 \%$ \\
Chang (1990) & 165 & $1976-1987$ & $3.7 \%$ \\
Chang and Mayers (1992) & 276 & $1976-1989$ & $0.7 \%$ \\
\hline
\end{tabular}

Table 8 also reports CARs disaggregated by the union status of the firm. For the 120 nonunionized firms, the CARs are slightly smaller for the overall sample of firms. The CARs for the 27 unionized firms are around fifty percent larger than for the nonunion sample. For the unionized firms, the CARs are 2.4\% for the interval $(-5,5), 2.3 \%$ for the interval $(-5,1)$, and $1.7 \%$

\footnotetext{
${ }^{23}$ The ESOP sample declines from 602 to 147 when we restrict ourselves to ESOPs where we know the announcement date. This dating information is important for conducting an event study of the stock market reaction to the announcement of the ESOP.
} 
for the interval $(-2,1)$.

In order to gain additional insights into these results, we further divide the sample by whether the ownership share in their ESOP is greater or less than 8.5\%. For the union sample, we find a sharp contrast in the announcement effects for unionized firms depending on the size of the ESOP. For unionized firms that adopt small ESOPs $(<8.5 \%)$, there is no significant market reaction to the ESOP announcement. In contrast, for unionized firms that adopt large ESOPs (> 8.5\%), the market reaction is quite strong. The CARs in these cases range from 3.3\% to $3.9 \%$ depending on the event window. ${ }^{24}$ In contrast, we do not find a sharp difference in announcement effects by ESOP size for the sample of nonunion firms. Whatever the benefits are to firms in general from establishing an ESOP, the benefits are considerably larger for unionized firms, and in particular for unionized firms that establish large ESOPs. ${ }^{25}$ To our knowledge, this feature of the data has not been previously noted in the literature.

The calibration results displayed in Figure 4 offer some insights into this finding. The costs to current shareholders of the firm giving employees an equity stake are the same regardless of the union status of the firm. Union and nonunion firms likely benefit equally from the tax advantages afforded by establishing an ESOP. If there are important productivity effects associated with ESOPs, it is less clear that they would be equally shared by non-union and union firms. However, the calibration exercise clearly illustrates that the expected bargaining losses associated with labor disputes declines with the size of the union's equity stake. This creates a differential value of an ESOP to union firms which if understood by investors should be capitalized in the announcement effect.

\section{Conclusion}

Firms and unions that repeatedly negotiate labor contracts have an incentive to adopt forms of compensation that minimize the renegotiation costs. The adoption of multi-year contracts with prespecified deferred payments and a cost-of-living clause is one example. By extending the contract duration the costs of renegotiation can be amortized over a longer time period. Similarly, ESOPs may alter the incentives of the firm and union in ways that help to

\footnotetext{
${ }^{24}$ For the sample of nonunion firms, there is no difference in announcement effects between large and small ESOPs.
} 
minimize the frequency and costs of labor disputes. Given the recent growth of ESOPs for unionized firms, the impact of ESOPs on the collective bargaining process is an important area of research.

In this paper, we argue that ESOPs may lead to lower dispute rates, and fewer strikes as a fraction of total disputes. The presence of an ESOP changes the incentives of the union since it no longer collects its rents exclusively through the negotiated wage. We examine the impact of ESOPs on collective bargaining outcomes by extending the signaling model of Cramton and Tracy (1992) to allow the union to hold an equity stake in the firm. The model predicts that increasing the size of the union's equity stake acts to more closely align the union's interests with the interests of the firm. A consequence is a reduction in labor disputes and a shift by the union away from the more costly strike threat and towards the holdout threat.

Using data on major collective bargaining negotiations from 1970-1995, we find evidence consistent with the prediction that ESOPs reduce the overall incidence of strikes and labor disputes. For large ESOPs, the data also suggest that ESOPs shift the composition of disputes away from strikes and toward holdouts. The theory suggests that shareholders of unionized firms should experience a differential gain from the adoption of an ESOP. We verify this by conducting an event study of the stock market reaction to ESOP adoptions. We find that the stock market reaction to a unionized ESOP adoption is 50\% larger than for a non-union ESOP adoption. These findings indicate that ESOPs may provide firms and unions with a tool to improve the efficiency with which they renegotiate labor agreements. A more complete picture requires more data on post-ESOP contract negotiations and detailed information on pre- and post-ESOP wage settlements.

\footnotetext{
${ }^{25}$ To check the robustness of the results, we used a 5\% size cutoff for the large ESOPs. With this lower size cutoff, the overall findings qualitatively remain the same.
} 


\section{References}

Admati, Anat R., and Motty Perry. "Strategic Delay in Bargaining.” Review of Economic Studies 54 (July 1987): 345-364.

Beatty, Anne. "The Cash Flow and Informational Effects of Employee Stock Ownership Plans.” Journal of Financial Economics 38 (1995): 525-556.

Bell, Linda, and Douglas Kruse. "Evaluating ESOPs, Profit-Sharing and Gain Sharing Plans in U.S. Industries: Effects on Worker and Company Performance.” Submitted to: The Office of the American Workplace, U.S. Department of Labor, May, 1995.

Ben-Ner, Avner, and Byoung Jun. "Employee Buyout in a Bargaining Game with Asymmetric Information.” American Economic Review 86 (June 1996): 502-523.

Chang, Saeyoung. "Employee Stock Ownership Plans and Shareholder Wealth: An Empirical Investigation.” Financial Management 19 (Spring 1990): 48-58.

------, and David Mayers. "Managerial Vote Ownership and Shareholder Wealth.” Journal of Financial Economics 32 (1992): 103-131.

Chaplinsky, Susan, and Greg Niehaus. "The Role of ESOPs in Takeover Contests.” Journal of Finance 49 (September 1994): 1451-1470.

Cott, Jeremy, and Stuart C. Gilson, Harvard Business School. “UAL Corporation.” 9-295-130, April, 1995.

Cramton, Peter, and Joseph S. Tracy. "Strikes and Holdouts in Wage Bargaining: Theory and Data.” American Economic Review 82 (March 1992): 100-121.

------, “The Determinants of U.S. Labor Disputes,” Journal of Labor Economics, 12 (1994): 180209.

Flanagan, Robert J. “Wage Concessions and Long-Term Union Wage Flexibility.” Brookings Paper on Economic Activity 1984, no. 1 (1984): 183-216.

Gordon, Lilli A., and John Pound. "ESOPs and Corporate Control.” Journal of Financial Economics 27 (1990): 525-555.

Kruse, Douglas. Profit Sharing: Does It Make A Difference? Kalamazoo, MI, W.E. UpJohn Institute for Employment Research, 1993.

------, and Joseph Blasi. "Employee Ownership, Employee Attitudes, and Firm Performance.” NBER Working Paper Nol 5277, September, 1995.

MacKinlay, A. Craig. “Event Studies in Economics and Finance.” Journal of Economic Literature 35 (March 1997): 13-39.

Oringer, Andrew L., Clifford Chance Rogers \& Wells LLP. Employee Stock Ownership Plans - An Overview, 2001.

Rosen, Corey, David Snyder, and Karen M. Young. Voting and Board Participation and Employee Controlled Firms. The National Center for Employee Ownership, 1993.

Rubinstein, Ariel. "Perfect Equilibrium in a Bargaining Model.” Econometrica 50 (January 1982): 97-109.

Scholes, Myron S., and Mark A. Wolfson. "Employee Stock Ownership Plans and Corporate Restructuring: Myths and Realities.” Financial Management, Spring 1990, 12-28.

Sellers, Keith, Joseph Hagan, and Philip Siegel. "Employee Stock Ownership Plans and Shareholder Wealth: An Examination of the Market Perceptions of the Non-Tax Effect.” Journal of Applied Business Research 10 (1994): 45-52.

U.S. Department of Labor. "Private Pension Plan Bulletin: Abstract of 1995 Form 5500 Annual Reports.” Pension and Welfare Benefits Administration, U.S. Department of Labor. Private Pension Plan Bulletin. 
U.S. Government Accounting Office. “Employee Stock Ownership.” GAO-PEMD-86-4BR, February, 1986. 
Table 1: Adoption of ESOPs - by Year

\begin{tabular}{|c|c|c|}
\hline Year & $\begin{array}{c}\text { Number of } \\
\text { Bargaining Units } \\
\text { Adopting }\end{array}$ & Percent of Total \\
\hline 1975 & 3 & 2.1 \\
\hline 1976 & 1 & 0.7 \\
\hline 1977 & 0 & 0 \\
\hline 1978 & 0 & 0 \\
\hline 1979 & 1 & 0.7 \\
\hline 1980 & 0 & 0 \\
\hline 1981 & 0 & 0 \\
\hline 1982 & 1 & 0.7 \\
\hline 1983 & 0 & 0 \\
\hline 1984 & 5 & 3.5 \\
\hline 1985 & 4 & 2.8 \\
\hline 1986 & 1 & 0.7 \\
\hline 1987 & 2 & 1.4 \\
\hline 1988 & 2 & 1.4 \\
\hline 1989 & 58 & 40.8 \\
\hline 1990 & 10 & 7.0 \\
\hline 1991 & 54 & 38.0 \\
\hline 1992 & 0 & 0 \\
\hline 1993 & 0 & 0 \\
\hline 1994 & 0 & 0 \\
\hline 1995 & 0 & 0 \\
\hline & 142 & 100 \\
\hline
\end{tabular}


Table 2: Adoption of ESOPs - by Industry

\begin{tabular}{|c|c|c|c|}
\hline Industry & $\begin{array}{l}\text { Number of } \\
\text { Bargaining Units } \\
\text { Adopting }\end{array}$ & $\begin{array}{c}\text { Percent of Total } \\
\text { ESOPs }\end{array}$ & $\begin{array}{l}\text { Percent of BU's in } \\
\text { Industry }\end{array}$ \\
\hline Food & 9 & 6.3 & 7.3 \\
\hline Lumber & 1 & 6.7 & 1.2 \\
\hline Paper & 14 & 9.9 & 4.0 \\
\hline Printing & 5 & 3.5 & 2.3 \\
\hline Chemicals & 9 & 6.3 & 2.5 \\
\hline Petroleum \& Coal & 9 & 6.3 & 1.6 \\
\hline Rubber & 2 & 1.4 & 1.6 \\
\hline Stone, Clay \& Glass & 1 & 0.7 & 2.1 \\
\hline Primary Metals & 12 & 8.4 & 5.5 \\
\hline Fabricated Metals & 6 & 4.2 & 2.6 \\
\hline $\begin{array}{r}\text { Machinery, ex. } \\
\text { Elec. }\end{array}$ & 9 & 6.3 & 3.9 \\
\hline Electrical Eq. & 16 & 11.3 & 5.1 \\
\hline Transportation Eq. & 30 & 21.1 & 6.8 \\
\hline Instruments & 2 & 1.4 & 0.9 \\
\hline Misc. Mfg. & 2 & 1.4 & 0.7 \\
\hline Transportation & 11 & 7.7 & 3.7 \\
\hline \multirow[t]{2}{*}{ Communications } & 3 & 2.1 & 4.2 \\
\hline & 142 & 100 & \\
\hline
\end{tabular}


Table 3. Labor Dispute Rates - by ESOP status

\begin{tabular}{|c|c|c|c|}
\hline & $\begin{array}{c}\text { Strike } \\
\text { Incidence }\end{array}$ & $\begin{array}{c}\text { Dispute } \\
\text { Incidence }^{\mathrm{a}} \\
\end{array}$ & $\begin{array}{c}\text { Dispute } \\
\text { Composition }^{\mathrm{b}}\end{array}$ \\
\hline $\begin{array}{l}\text { Overall } \\
{[8,665]}\end{array}$ & $\begin{array}{l}12.1 \\
(0.3)\end{array}$ & $\begin{array}{l}49.4 \\
(0.5)\end{array}$ & $\begin{array}{l}24.5 \\
(0.7)\end{array}$ \\
\hline $\begin{array}{l}\text { No ESOP } \\
{[7,663]}\end{array}$ & $\begin{array}{l}11.9 \\
(0.4)\end{array}$ & $\begin{array}{l}50.3 \\
(0.6)\end{array}$ & $\begin{array}{l}23.6 \\
(0.7)\end{array}$ \\
\hline $\begin{array}{l}\text { Pre-1989 } \\
{[6,084]}\end{array}$ & $\begin{array}{l}13.1 \\
(0.4)\end{array}$ & $\begin{array}{l}48.5 \\
(0.6)\end{array}$ & $\begin{array}{l}27.1 \\
(0.8)\end{array}$ \\
\hline $\begin{array}{l}\text { Post-1989 } \\
{[1,579]}\end{array}$ & $\begin{array}{c}7.0 \\
(0.8)\end{array}$ & $\begin{array}{l}57.3 \\
(1.2)\end{array}$ & $\begin{array}{l}12.1 \\
(1.4)\end{array}$ \\
\hline $\begin{array}{l}\text { Post-1989 - } \\
\text { Pre-1989 }\end{array}$ & $\begin{array}{l}-6.2^{* *} \\
(0.9)\end{array}$ & $\begin{array}{l}8.8^{* *} \\
(1.4)\end{array}$ & $\begin{array}{c}-15.0^{* *} \\
(1.6)\end{array}$ \\
\hline $\begin{array}{l}\text { Adopt ESOP } \\
\text { Pre-ESOP } \\
{[924]}\end{array}$ & $\begin{array}{l}14.5 \\
(1.1)\end{array}$ & $\begin{array}{l}41.9 \\
(1.6)\end{array}$ & $\begin{array}{l}34.6 \\
(2.2)\end{array}$ \\
\hline $\begin{array}{l}\text { Post-ESOP } \\
{[78]}\end{array}$ & $\begin{array}{c}6.4 \\
(3.7)\end{array}$ & $\begin{array}{l}46.1 \\
(5.6)\end{array}$ & $\begin{array}{l}13.9 \\
(7.1)\end{array}$ \\
\hline $\begin{array}{l}\text { Post-ESOP - } \\
\text { Pre-ESOP }\end{array}$ & $\begin{array}{l}-8.1^{* *} \\
(3.8)\end{array}$ & $\begin{array}{c}4.2 \\
(5.9)\end{array}$ & $\begin{array}{c}-20.7^{* *} \\
(7.4)\end{array}$ \\
\hline ESOP impact $^{c}$ & $\begin{array}{l}-1.9 \\
(3.9)\end{array}$ & $\begin{array}{l}-4.6 \\
(6.0) \\
\end{array}$ & $\begin{array}{l}-5.7 \\
(7.6) \\
\end{array}$ \\
\hline
\end{tabular}

Notes: Sample sizes given in brackets and standard errors are given in parentheses.

${ }^{a}$ Dispute incidence is the ratio of strikes and holdouts to contract negotiations.

${ }^{\mathrm{b}}$ Dispute composition is the ratio of strike to disputes.

${ }^{\mathrm{c}}$ ESOP impact $=($ Post-ESOP - Pre-ESOP $)-($ Post-1989 - Pre-1989 $)$.

significant at the $5 \%$ level. 
Table 4: Impact of ESOPs on Collective Bargaining

\begin{tabular}{|c|c|c|c|}
\hline & $\begin{array}{c}\text { Strike } \\
\text { Incidence }\end{array}$ & $\begin{array}{c}\text { Dispute } \\
\text { Incidence }^{\mathrm{a}}\end{array}$ & $\begin{array}{c}\text { Dispute } \\
\text { Composition }^{b}\end{array}$ \\
\hline & $(1)$ & (2) & (3) \\
\hline Pre-ESOP & $\begin{array}{l}-0.059 \\
(0.112)\end{array}$ & $\begin{array}{l}-0.067 \\
(0.053)\end{array}$ & $\begin{array}{c}0.093 \\
(0.131)\end{array}$ \\
\hline Post-ESOP & $\begin{array}{l}-0.139 \\
(0.180)\end{array}$ & $\begin{array}{l}-0.123 \\
(0.093)\end{array}$ & $\begin{array}{l}-0.088 \\
(0.270)\end{array}$ \\
\hline $\begin{array}{r}\text { Industry Employment } \\
\text { Residual }\end{array}$ & $\begin{array}{l}-0.033^{* *} \\
(0.004)\end{array}$ & $\begin{array}{l}-0.006 \\
(0.004)\end{array}$ & $\begin{array}{c}-0.039^{* *} \\
(0.011)\end{array}$ \\
\hline $\begin{array}{r}\text { Industry Employment } \\
\text { Trend }\end{array}$ & $\begin{array}{c}0.029 \\
(0.025)\end{array}$ & $\begin{array}{l}0.019^{*} \\
(0.010)\end{array}$ & $\begin{array}{c}0.015 \\
(0.033)\end{array}$ \\
\hline $\begin{array}{r}\text { State Employment } \\
\text { Residual }\end{array}$ & $\begin{array}{c}0.023 \\
(0.015)\end{array}$ & $\begin{array}{c}0.005 \\
(0.004)\end{array}$ & $\begin{array}{c}0.006 \\
(0.018)\end{array}$ \\
\hline $\begin{array}{r}\text { State Employment } \\
\text { Trend }\end{array}$ & $\begin{array}{l}-0.037 \\
(0.049)\end{array}$ & $\begin{array}{l}-0.044^{*} \\
(0.023)\end{array}$ & $\begin{array}{c}0.031 \\
(0.060)\end{array}$ \\
\hline Bargaining Unit Size & $\begin{array}{c}0.020 \\
(0.018)\end{array}$ & $\begin{array}{l}-0.019 \\
(0.017)\end{array}$ & $\begin{array}{c}0.030 \\
(0.021)\end{array}$ \\
\hline Sample Size & 4,462 & 7,732 & 2,233 \\
\hline ESOP Impact $^{\mathrm{c}}$ & -0.080 & -0.056 & -0.181 \\
\hline $\begin{array}{r}\chi^{2}(\text { ESOP Impact }=0) \\
{[\text { Probability Value }]}\end{array}$ & $\begin{array}{c}0.30 \\
{[0.59]}\end{array}$ & $\begin{array}{c}0.77 \\
{[0.38]}\end{array}$ & $\begin{array}{c}0.65 \\
{[0.42]}\end{array}$ \\
\hline
\end{tabular}

Notes: Conditional logit marginal effects and standard errors. The marginal effects assume a bargaining unit fixed effect equal to zero. Specifications control for year effects.

${ }^{a}$ Dispute incidence is the ratio of strikes and holdouts to contract negotiations.

${ }^{\mathrm{b}}$ Dispute composition is the ratio of strike to disputes.

${ }^{\mathrm{c}}$ ESOP impact $=$ Post-ESOP - Pre-ESOP

${ }^{* *}$ significant at the $5 \%$ level $^{*}$ significant at the $10 \%$ level 
Table 5: Comparison of Theoretical and Empirical Impact of ESOPs on Collective Bargaining

\begin{tabular}{lccc}
\hline \hline & Dispute Incidence & Strike Incidence & Dispute Composition \\
\hline Pre-ESOP (theory) & 51.8 & 11.1 & 21.4 \\
Post-ESOP (theory) & 51.6 & 5.5 & 10.7 \\
ESOP Impact (theory) & -0.2 & -5.6 & -10.7 \\
ESOP Impact (estimated) & -5.6 & -8.0 & -18.1 \\
\hline Notes: The theoretical impact of an ESOP is calculated from the benchmark model of section 3, \\
using the empirical distribution of ESOP ownership shares. The estimated ESOP impact is from \\
Table 4.
\end{tabular}


Table 6: Impact of ESOPs on Collective Bargaining - by size of ESOP

\begin{tabular}{|c|c|c|c|}
\hline & $\begin{array}{c}\text { Strike } \\
\text { Incidence }\end{array}$ & $\begin{array}{c}\text { Dispute } \\
\text { Incidence }^{\mathrm{a}}\end{array}$ & $\begin{array}{c}\text { Dispute } \\
\text { Composition }^{\mathrm{b}}\end{array}$ \\
\hline & (1) & (2) & (3) \\
\hline Pre-ESOP, < 8.5\% & $\begin{array}{l}-0.047 \\
(0.123)\end{array}$ & $\begin{array}{l}-0.066 \\
(0.058)\end{array}$ & $\begin{array}{c}0.103 \\
(0.147)\end{array}$ \\
\hline Post-ESOP, < 8.5\% & $\begin{array}{l}-0.198 \\
(0.283)\end{array}$ & $\begin{array}{l}-0.141 \\
(0.136)\end{array}$ & $\begin{array}{c}0.165 \\
(0.274)\end{array}$ \\
\hline Pre-ESOP, > 8.5\% & $\begin{array}{l}-0.073 \\
(0.126)\end{array}$ & $\begin{array}{l}-0.070 \\
(0.062)\end{array}$ & $\begin{array}{c}0.083 \\
(0.149)\end{array}$ \\
\hline Post-ESOP, > 8.5\% & $\begin{array}{l}-0.121 \\
(0.200)\end{array}$ & $\begin{array}{l}-0.117 \\
(0.101)\end{array}$ & $\begin{array}{l}-0.253 \\
(0.298)\end{array}$ \\
\hline $\begin{array}{r}\text { Industry Employment } \\
\text { Residual }\end{array}$ & $\begin{array}{l}-0.033^{* *} \\
(0.009)\end{array}$ & $\begin{array}{l}-0.006 \\
(0.004)\end{array}$ & $\begin{array}{l}-0.039^{* *} \\
(0.011)\end{array}$ \\
\hline $\begin{array}{r}\text { Industry Employment } \\
\text { Trend }\end{array}$ & $\begin{array}{c}0.030 \\
(0.025)\end{array}$ & $\begin{array}{l}0.019^{*} \\
(0.010)\end{array}$ & $\begin{array}{c}0.015 \\
(0.033)\end{array}$ \\
\hline $\begin{array}{r}\text { State Employment } \\
\text { Residual }\end{array}$ & $\begin{array}{c}0.023 \\
(0.015)\end{array}$ & $\begin{array}{c}0.005 \\
(0.004)\end{array}$ & $\begin{array}{c}0.007 \\
(0.018)\end{array}$ \\
\hline $\begin{array}{r}\text { State Employment } \\
\text { Trend }\end{array}$ & $\begin{array}{l}-0.037 \\
(0.049)\end{array}$ & $\begin{array}{l}-0.045^{*} \\
(0.023)\end{array}$ & $\begin{array}{c}0.031 \\
(0.060)\end{array}$ \\
\hline Bargaining Unit Size & $\begin{array}{c}0.020 \\
(0.178)\end{array}$ & $\begin{array}{l}-0.019 \\
(0.017)\end{array}$ & $\begin{array}{c}0.030 \\
(0.021)\end{array}$ \\
\hline Sample Size & 4,462 & 7,732 & 2,233 \\
\hline ESOP Impact, $<8.5 \%{ }^{\mathrm{c}}$ & -0.151 & -0.075 & 0.062 \\
\hline $\begin{array}{r}\chi^{2}(\text { ESOP Impact, }<8.5 \%=0) \\
{[\text { Probability Value }]}\end{array}$ & $\begin{array}{c}0.31 \\
{[0.58]}\end{array}$ & $\begin{array}{c}0.46 \\
{[0.50]}\end{array}$ & $\begin{array}{c}0.06 \\
{[0.81]}\end{array}$ \\
\hline ESOP Impact, $>8.5 \%^{\mathrm{c}}$ & -0.048 & -0.047 & -0.336 \\
\hline $\begin{array}{r}\chi^{2}(\text { ESOP Impact, }>8.5 \%=0) \\
{[\text { Probability Value }]}\end{array}$ & $\begin{array}{c}0.08 \\
{[0.78]}\end{array}$ & $\begin{array}{c}0.39 \\
{[0.53]}\end{array}$ & $\begin{array}{c}1.19 \\
{[0.27]}\end{array}$ \\
\hline
\end{tabular}

Notes: Conditional logit marginal effects and standard errors. The marginal effects assume a bargaining unit fixed effect equal to zero. Specifications control for year effects.

${ }^{a}$ Dispute incidence is the ratio of strikes and holdouts to contract negotiations.

${ }^{\mathrm{b}}$ Dispute composition is the ratio of strike to disputes.

${ }^{\mathrm{c}}$ ESOP impact $=$ Post-ESOP - Pre-ESOP

${ }^{* *}$ significant at the $5 \%$ level $^{*}$ significant at the $10 \%$ level 
Table 7. Descriptive statistics of the sample characteristics

\begin{tabular}{lrrrrr}
\hline \multicolumn{1}{c}{ Variable } & Sample Size & Mean & Median & Min & Max \\
\hline Employment (thousands) & & & & & \\
All & 147 & 20.9 & 4.8 & .1 & 520.0 \\
Non-union & 120 & 16.1 & 2.8 & .1 & 520.0 \\
Union & 27 & 42.0 & 24.7 & 2.3 & 186.8 \\
Book Value of Assets (\$ millions) & & & & & \\
All & 83 & $4,974.7$ & 799.0 & 7.8 & $61,768.8$ \\
Non-union & 62 & $3,072.1$ & 538.0 & 7.8 & $52,984.0$ \\
Union & 21 & $10,592.0$ & $4,274.9$ & 330.2 & $61,768.8$ \\
Market Value / Book Value & & & & & \\
All & & & & & \\
Non-union & 141 & 1.3 & 1.2 & 0.8 & 2.9 \\
Union & 115 & 1.3 & 1.2 & 0.8 & 2.9 \\
All & 26 & 1.3 & 1.2 & 0.8 & 2.1 \\
Non-union & & & & & \\
Union & 151 & 11.6 & 8.0 & .1 & 75.5 \\
& 124 & 11.6 & 8.0 & .1 & 75.5 \\
ESOP (\%) & 27 & 11.7 & 7.0 & 2.4 & 60.0 \\
\hline
\end{tabular}

Notes:

${ }^{\text {a }}$ Sample size indicates non-missing variables in COMPUSTAT.

${ }^{\mathrm{b}}$ Defined as price-close calendar year times shares outstanding plus total assets minus common equity all divided by book value of assets. 
Table 8. Cumulative average abnormal returns (CAR)

\begin{tabular}{lcccc}
\hline \multicolumn{1}{c}{ Window } & Sample & $(5,5)$ & $(5,1)$ & $(2,1)$ \\
\hline Overall & 147 & $\begin{array}{l}0.016^{* *} \\
(0.007)\end{array}$ & $\begin{array}{c}0.015^{* *} \\
(0.006)\end{array}$ & $\begin{array}{c}0.013^{* *} \\
(0.004)\end{array}$ \\
Nonunion & & & & \\
& 120 & $0.015^{*}$ & $0.013^{*}$ & $0.012^{* *}$ \\
& & $(0.008)$ & $(0.007)$ & $(0.005)$ \\
Large ESOP & 57 & 0.013 & 0.011 & $0.012^{*}$ \\
& & $(0.011)$ & $(0.009)$ & $(0.007)$ \\
Small ESOP & 63 & 0.009 & 0.008 & $0.010^{*}$ \\
& & $(0.009)$ & $(0.007)$ & $(0.005)$ \\
Union & & & & \\
& 27 & $0.024^{*}$ & $0.023^{* *}$ & $0.017^{* *}$ \\
& & $(0.012)$ & $(0.010)$ & $(0.007)$ \\
Large ESOP & 15 & $0.044^{* *}$ & $0.039^{* *}$ & $0.036^{* *}$ \\
& & $(0.018)$ & $(0.015)$ & $(0.011)$ \\
Small ESOP & \multirow{2}{*}{12} & -0.001 & 0.003 & -0.006 \\
& & $(0.016)$ & $(0.013)$ & $(0.009)$ \\
\hline
\end{tabular}

Notes: ESOP announcement day $(\mathrm{t}=-1)$. Numbers in parentheses are standard errors. CARs estimated using the market model discussed in MacKinlay (1997). Parameters of the model are calculated using returns over the period -260 to -61 and 61 to 260 .

** significant at the $5 \%$ level, ${ }^{*}$ significant at the $10 \%$ level 
Figure 1. ESOP Ownership Shares for Unionized Firms

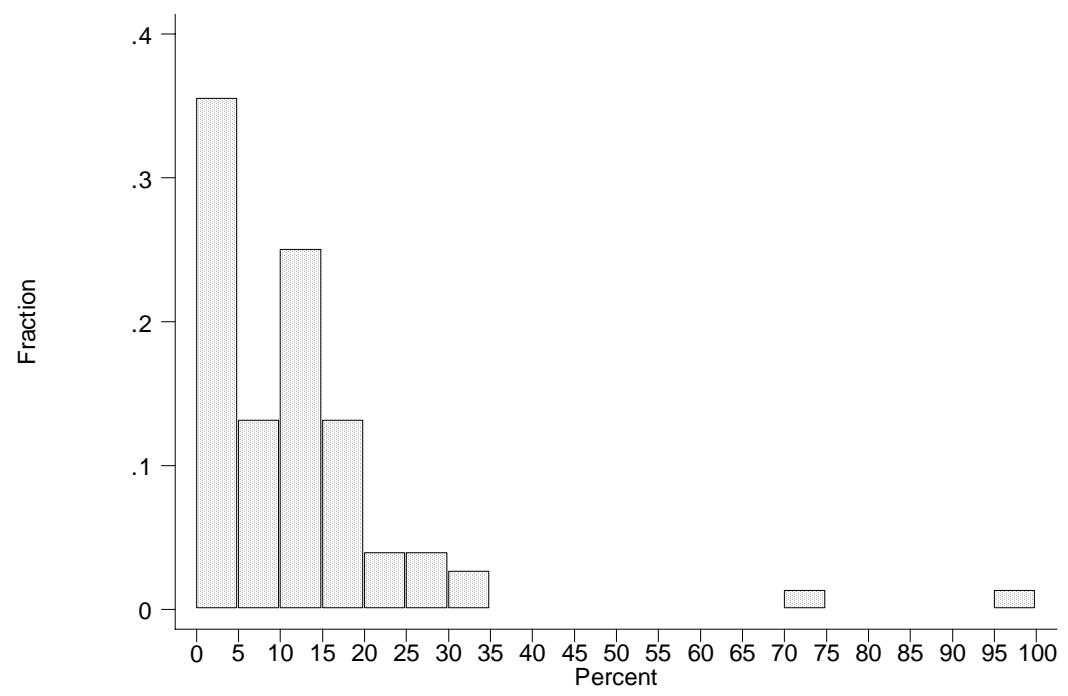

Figure 2. Payoffs from Bargaining Outcome $\langle t, w, \theta\rangle$ with an ESOP of size $\alpha$

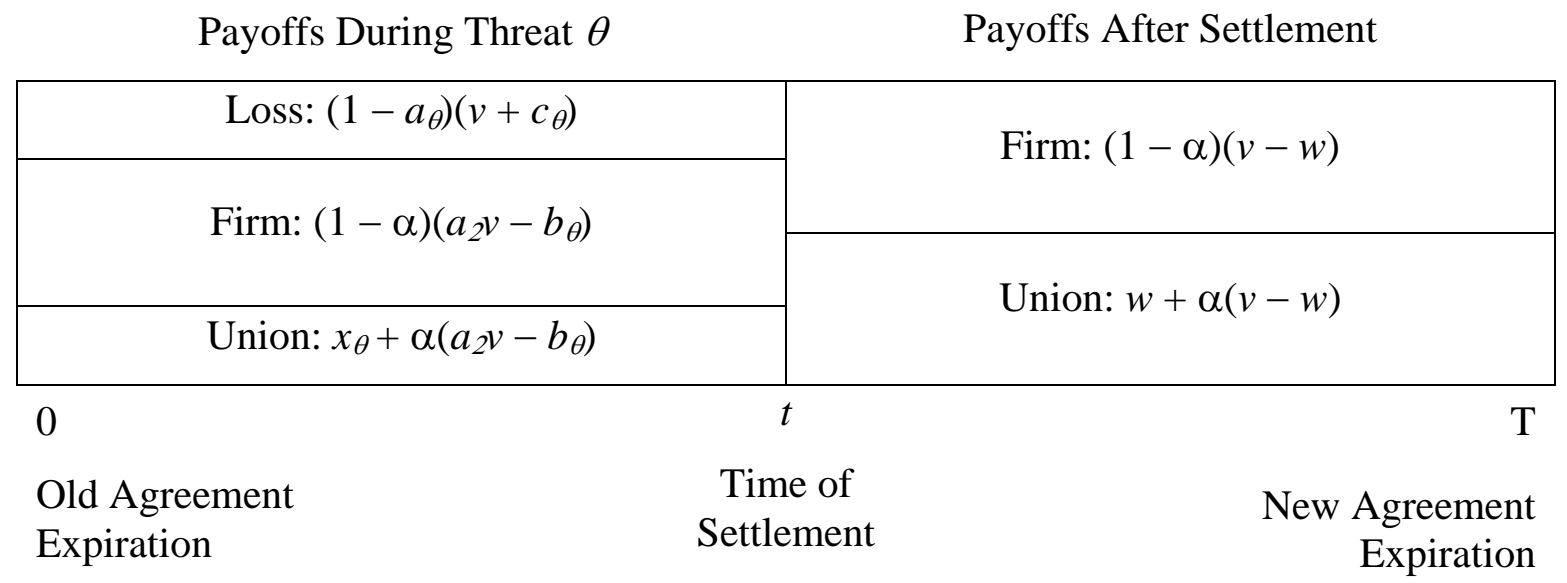


Figure 3. Dispute Incidence as a Function of ESOP Ownership Share

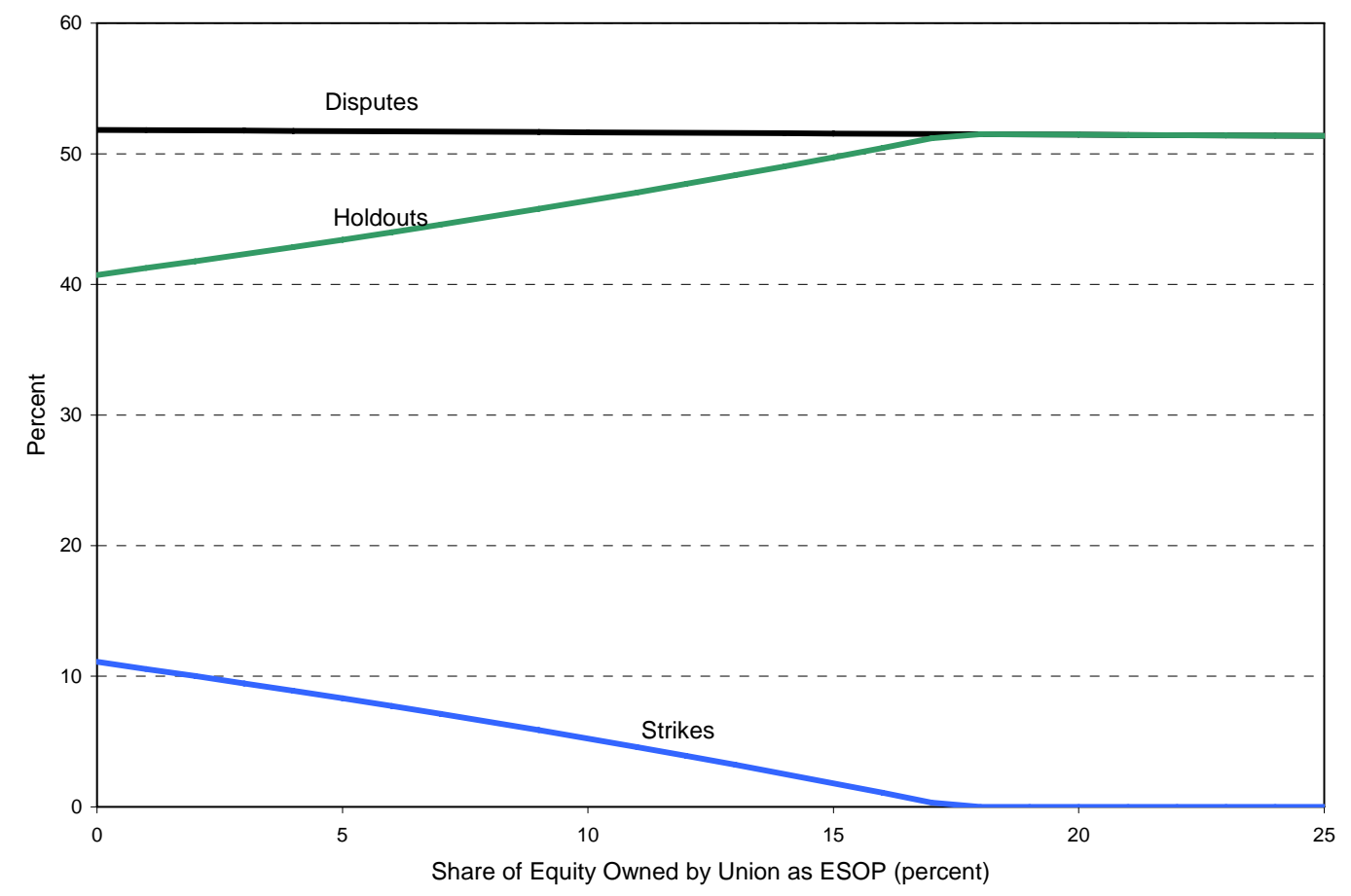

Figure 4. Expected Loss from Dispute as a Function of ESOP Ownership Share

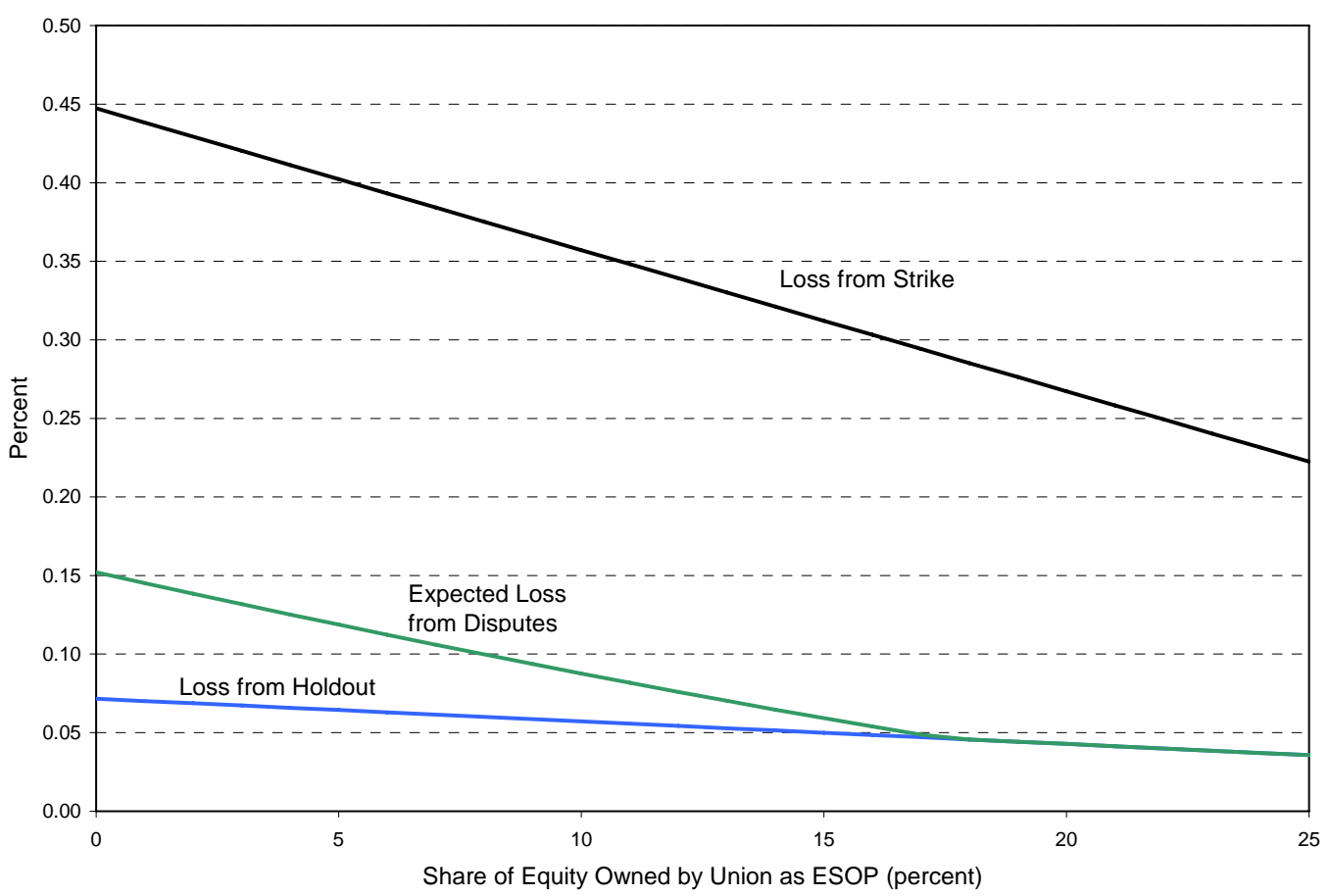




\section{Appendix A}

The proofs of Propositions 1-3 are extensions of similar propositions in Cramton and Tracy (1992). As a result only a sketch of the proofs are given.

Proof of Proposition 1. We begin by establishing the Rubinstein wage when the union has an ESOP of size $\alpha$. Then the payoffs during the threat $\theta$ and after settlement are as shown in Figure 1. The Rubinstein wage is determined from a pair of indifference relations, which require the firm offers a wage $w_{f}$ and union offers wage $w_{u}$, such that each is indifferent between immediate acceptance of the other's offer or waiting and having the other accept their offer after a period of delay. Let $\delta$ be the discount factor between offers. Then the indifference relations for the union and firm are

$$
\begin{gathered}
w_{f}+\alpha\left(v-w_{f}\right)-x_{\theta}-\alpha\left(a_{\theta} v-b_{\theta}\right)=\delta\left(w_{u}+\alpha\left(v-w_{u}\right)-x_{\theta}-\alpha\left(a_{\theta} v-b_{\theta}\right)\right) \\
(1-\alpha)\left(v-w_{u}-a_{\theta} v+b_{\theta}\right)=\delta(1-\alpha)\left(v-w_{f}-a_{\theta} v+b_{\theta}\right) .
\end{gathered}
$$

Solving for the wage offers yields

$$
\begin{aligned}
& w_{f}=\frac{\delta\left(\left(1-a_{\theta}\right) v+b_{\theta}\right)+x_{\theta}}{(1+\delta)(1-\alpha)}-\frac{\alpha}{1-\alpha}\left(\left(1-a_{\theta}\right) v+b_{\theta}\right) \\
& w_{u}=\frac{\left(1-a_{\theta}\right) v+b_{\theta}+\delta x_{\theta}}{(1+\delta)(1-\alpha)}-\frac{\alpha}{1-\alpha}\left(\left(1-a_{\theta}\right) v+b_{\theta}\right)
\end{aligned}
$$

Finally, letting the time between offers go to zero ( $\delta \rightarrow 1$ ), gives us the Rubinstein wage for the threat $\theta$ :

$$
\begin{aligned}
w_{f} & =w_{u}=\frac{1}{1-\alpha}\left(\frac{x_{\theta}}{2}+\left(\frac{1}{2}-\alpha\right)\left(\left(1-a_{\theta}\right) v+b_{\theta}\right)\right) \\
& =\frac{1}{1-\alpha}\left(\frac{x_{\theta}}{2}+\left(\frac{1}{2}-\alpha\right)\left(\left(1-a_{\theta}\right) v+\left(1-a_{\theta}\right) c_{\theta}+x_{\theta}\right)\right) \\
& =\frac{1}{1-\alpha}\left((1-\alpha) x_{\theta}+\left(\frac{1}{2}-\alpha\right)\left(1-a_{\theta}\right)\left(v+c_{\theta}\right)\right) \\
& =x_{\theta}+\frac{1-2 \alpha}{2-2 \alpha}\left(1-a_{\theta}\right)\left(v+c_{\theta}\right) .
\end{aligned}
$$

Next we need to determine the firm's optimal choice of delay, which credibly reveals its type. When the firm rejects the union's offer $p$, it makes the offer $w_{\theta}(v)$ after delaying for $D(t)$ of the contract period. The new contract expires at time $T$. Define

$$
D(\Delta) \equiv \frac{1-e^{-r \Delta}}{1-e^{-r T}} .
$$

The firm selects the delay $\Delta$ to maximize its profits: 


$$
\begin{aligned}
& \max _{\Delta}\left[D(\Delta)(1-\alpha)\left(a_{\theta} v-b_{\theta}\right)+(1-D(\Delta))(1-\alpha)\left(v-w_{\theta}\right)\right] \\
& =\max _{\Delta} \frac{1-\alpha}{1-e^{-r T}}\left[\left(1-e^{-r \Delta}\right)\left(a_{\theta} v-b_{\theta}\right)+\left(e^{-r \Delta}-e^{-r T}\right)\left(v-x_{\theta}-\frac{1-2 \alpha}{2-2 \alpha}\left(1-a_{\theta}\right)\left(v(\Delta)+c_{\theta}\right)\right)\right] \\
& =\max _{\Delta} \frac{1-\alpha}{1-e^{-r T}}\left[\left(1-e^{-r \Delta}\right) y_{\theta}+\left(e^{-r \Delta}-e^{-r T}\right)\left(v-w_{\theta}[v(\Delta)]\right)\right] .
\end{aligned}
$$

The first order condition is

where

$$
\begin{aligned}
& e^{-r \Delta}\left(r\left(y_{\theta}-v+w_{\theta}[v(\Delta)]\right)-\left(1-e^{-r(T-\Delta)}\right) w_{\theta}^{\prime}[v(\Delta)]\right)=0 \\
& \left.\Rightarrow r\left(v-w_{\theta}[v(\Delta)]-y_{\theta}\right)+\left(1-e^{-r(T-\Delta)}\right) w_{\theta}^{\prime}[v(\Delta)]\right)=0,
\end{aligned}
$$

$$
\begin{aligned}
& y_{\theta}=a_{\theta} v-b_{\theta} \\
& w_{\theta}(v)=x_{\theta}+\frac{1-2 \alpha}{2-2 \alpha}\left(1-a_{\theta}\right)\left(v+c_{\theta}\right) \\
& v-w_{\theta}[v(\Delta)]-y_{\theta}=\frac{1}{2-2 \alpha}\left(1-a_{\theta}\right)\left(v+c_{\theta}\right) \\
& w_{\theta}^{\prime}[v(\Delta)]=\frac{1-2 \alpha}{2-2 \alpha}\left(1-a_{\theta}\right) \frac{d v}{d \Delta} .
\end{aligned}
$$

Hence,

$$
\begin{aligned}
& r\left(v-w_{\theta}[v(\Delta)]-y_{\theta}\right)+\left(1-e^{-r(T-\Delta)}\right)(1-2 \alpha)\left(1-a_{\theta}\right) \frac{d v}{d \Delta}=0 \\
& \Rightarrow(1-D(t))^{\frac{1}{1-2 \alpha}}=\frac{v+c_{\theta}}{m+c_{\theta}} \\
& \Rightarrow 1-D(t)=\left(\frac{v+c_{\theta}}{m+c_{\theta}}\right)^{1-2 \alpha} \\
& \therefore D(v)=1-\left(\frac{v+c_{\theta}}{m+c_{\theta}}\right)^{1-2 \alpha} .
\end{aligned}
$$

The final step in the equilibrium construction is to determine the cutoff value $m$. When the union makes the initial offer $w_{\theta}(m)=x_{\theta}+\frac{1-2 \alpha}{2-2 \alpha}\left(1-a_{\theta}\right)\left(m+c_{\theta}\right)$, then the firm immediately accepts the union's offer if $v \geq m$. Otherwise, the firm with value $v$ delays until $D(v)$ of the contract has passed. The union's utility if there is a dispute is 


$$
\begin{aligned}
& =(1-D(v))\left(w_{\theta}(v)+\alpha\left(v-w_{\theta}(v)\right)\right)+D(v)\left(x_{\theta}+\alpha\left(a_{\theta} v-b_{\theta}\right)\right) \\
& =(1-D(v))\left((1-\alpha) x_{\theta}+\alpha v+\left(\frac{1}{2}-\alpha\right)\left(1-a_{\theta}\right)\left(v+c_{\theta}\right)\right)+D(v)\left((1-\alpha) x_{\theta}+\alpha v-\alpha\left(1-a_{\theta}\right)\left(v+c_{\theta}\right)\right) \\
& =(1-\alpha) x_{\theta}+\alpha v-\alpha\left(1-a_{\theta}\right)\left(v+c_{\theta}\right)+\frac{1}{2}\left(1-a_{\theta}\right) \frac{\left(v+c_{\theta}\right)^{2-2 \alpha}}{\left(m+c_{\theta}\right)^{1-2 \alpha}} .
\end{aligned}
$$

The union's utility if there is no dispute is

$$
\begin{aligned}
& =w_{\theta}(m)+\alpha\left(v-w_{\theta}(m)\right) \\
& =(1-\alpha) x_{\theta}+\alpha v+\left(\frac{1}{2}-\alpha\right)\left(1-a_{\theta}\right)\left(m+c_{\theta}\right)
\end{aligned}
$$

Thus, the union's expected utility is

$$
\begin{aligned}
U(m) & =(1-\alpha) x_{\theta}+\alpha E[v]+\frac{1}{2}\left(1-a_{\theta}\right) \\
& \times\left\{(1-2 \alpha)\left(m+c_{\theta}\right)[1-F(m)]+\int_{l}^{m}\left[\frac{\left(v+c_{\theta}\right)^{2-2 \alpha}}{\left(m+c_{\theta}\right)^{1-2 \alpha}}-2 \alpha\left(v+c_{\theta}\right)\right] d F(v)\right\}
\end{aligned}
$$

and the union chooses $m$ to maximize

$$
(1-2 \alpha)\left(m+c_{\theta}\right)[1-F(m)]+\int_{l}^{m}\left[\frac{\left(v+c_{\theta}\right)^{2-2 \alpha}}{\left(m+c_{\theta}\right)^{1-2 \alpha}}-2 \alpha\left(v+c_{\theta}\right)\right] d F(v)
$$

The first order condition for maximizing $m$ is

$$
\begin{aligned}
& (1-2 \alpha)(1-F(m))-(1-2 \alpha)\left(m+c_{\theta}\right) f(m)+(1-2 \alpha)\left(m+c_{\theta}\right) f(m)-(1-2 \alpha) \int_{l}^{m}\left(\frac{v+c_{\theta}}{m+c_{\theta}}\right)^{2-2 \alpha} d F(v)=0 \\
& \therefore 1-F(m)=\int_{l}^{m}\left(\frac{v+c_{\theta}}{m+c_{\theta}}\right)^{2-2 \alpha} d F(v) \\
& \Rightarrow 1-F(m)=F(m)\left(\frac{m+c_{\theta}}{m+c_{\theta}}\right)^{2-2 \alpha}-F(l)\left(\frac{l+c_{\theta}}{m+c_{\theta}}\right)^{2-2 \alpha}-2 \frac{1-\alpha}{m+c_{\theta}} \int_{l}^{m}\left(\frac{v+c_{\theta}}{m+c_{\theta}}\right)^{1-2 \alpha} F(v) d v \\
& \Rightarrow 1-F(m)=F(m)-2 \frac{1-\alpha}{m+c_{\theta}} \int_{l}^{m}\left(\frac{v+c_{\theta}}{m+c_{\theta}}\right)^{1-2 \alpha} F(v) d v \\
& \therefore F(m) \geq \frac{1}{2}
\end{aligned}
$$

Now,

$$
\begin{aligned}
& U^{\prime}(\mu)=\frac{1}{2}\left(1-a_{\theta}\right)\left[(1-2 \alpha)(1-F(\mu))-\int_{l}^{\mu}\left(\frac{v+c_{\theta}}{\mu+c_{\theta}}\right)^{2-2 \alpha} d F(v)\right] \\
& a_{\theta}<1 \& 0 \leq \alpha<\frac{1}{2} \Rightarrow U^{\prime}(l)>0 \& U^{\prime}(h)<0 .
\end{aligned}
$$

Since, $U^{\prime}($.$) is a continuous function, the maximum occurs at an interior point m$ such that the first-order condition is satisfied. In addition, the second-order condition must also be satisfied, so 


$$
\begin{aligned}
& U^{\prime \prime}(m)<0 \\
& \Rightarrow-f(m)-f(m)+(2-2 \alpha) \int_{l}^{m} \frac{\left(v+c_{\theta}\right)^{2-2 \alpha}}{\left(m+c_{\theta}\right)^{3-2 \alpha}} d F(v)<0 \\
& \therefore 1-(1-\alpha) \int_{l}^{m} \frac{\left(v+c_{\theta}\right)^{2-2 \alpha}}{\left(m+c_{\theta}\right)^{3-2 \alpha}} \frac{f(v)}{f(m)} d v>0 \\
& \Rightarrow\left(m+c_{\theta}\right) f(m)-(1-\alpha) \int_{l}^{m}\left(\frac{v+c_{\theta}}{m+c_{\theta}}\right)^{2-2 \alpha} d F(v)>0 \\
& \therefore\left(m+c_{\theta}\right) f(m)-(1-\alpha)(1-F(m))>0 .
\end{aligned}
$$

Proof of Proposition 2. First we show that dispute incidence falls with $\alpha$. From the first-order condition:

$$
\begin{aligned}
& 1-F(m(\alpha))=\int_{l}^{m(\alpha)}\left(\frac{v+c_{\theta}}{m(\alpha)+c_{\theta}}\right)^{2-2 \alpha} d F(v) \\
& \Rightarrow-f(m) \frac{d m}{d \alpha}=f(m) \frac{d m}{d \alpha}-2 \int_{l}^{m}\left(\frac{v+c_{\theta}}{m+c_{\theta}}\right)^{2-2 \alpha}\left(\log \left(\frac{v+c_{\theta}}{m+c_{\theta}}\right)+\frac{1-\alpha}{m+c_{\theta}} \frac{d m}{d \alpha}\right) f(v) d v \\
& \Rightarrow\left(-2 f(m)+2 \int_{l}^{m}(1-\alpha) \frac{\left(v+c_{\theta}\right)^{2-2 \alpha}}{\left(m+c_{\theta}\right)^{3-2 \alpha}} f(v) d v\right) \frac{d m}{d \alpha}=-2 \int_{l}^{m}\left(\frac{v+c_{\theta}}{m+c_{\theta}}\right)^{2-2 \alpha} \log \left(\frac{v+c_{\theta}}{m+c_{\theta}}\right) f(v) d v \\
& \therefore \frac{d m}{d \alpha}=\frac{\int_{l}^{m}\left(\frac{v+c_{\theta}}{m+c_{\theta}}\right)^{2-2 \alpha} \log \left(\frac{v+c_{\theta}}{m+c_{\theta}}\right) \frac{f(v)}{f(m)} d v}{1-\int_{l}^{m}(1-\alpha) \frac{\left(v+c_{\theta}\right)^{2-2 \alpha}}{\left(m+c_{\theta}\right)^{3-2 \alpha}} \frac{f(v)}{f(m)} d v} \\
& v \in[l, m] \Rightarrow \log \left(\frac{v+c_{\theta}}{m+c_{\theta}}\right) \leq 0
\end{aligned}
$$

$\therefore$ The numerator is negative and by the second order condition, the denominator is positive

$$
\therefore \frac{d m}{d \alpha}<0 \Rightarrow \frac{d F(m)}{d \alpha}<0 .
$$

Therefore, dispute incidence falls as $\alpha$ increases.

Now consider how dispute duration depends on $\alpha$ :

$$
\begin{aligned}
& D(\alpha)=1-\left(\frac{v+c_{\theta}}{m(\alpha)+c_{\theta}}\right)^{1-2 \alpha} \\
& \Rightarrow \frac{d D}{d \alpha}=-\left(\frac{v+c_{\theta}}{m+c_{\theta}}\right)^{1-2 \alpha}\left(-2 \log \left(\frac{v+c_{\theta}}{m+c_{\theta}}\right)-\frac{1-2 \alpha}{m+c_{\theta}} \frac{d m}{d \alpha}\right) \\
& \Rightarrow \frac{d D}{d \alpha}=\left(\frac{v+c_{\theta}}{m+c_{\theta}}\right)^{1-2 \alpha}\left(2 \log \left(\frac{v+c_{\theta}}{m+c_{\theta}}\right)+\frac{1-2 \alpha}{m+c_{\theta}} \frac{d m}{d \alpha}\right) \\
& \therefore \frac{d D}{d \alpha}<0 .
\end{aligned}
$$

Therefore, dispute duration falls as $\alpha$ increases. 
Now consider how dispute incidence depends on $c_{\theta}$ :

$$
\begin{aligned}
& 1-F\left(m\left(c_{\theta}\right)\right)=\int_{l}^{m\left(c_{\theta}\right)}\left(\frac{v+c_{\theta}}{m\left(c_{\theta}\right)+c_{\theta}}\right)^{2-2 \alpha} d F(v) \\
& \Rightarrow-f(m) \frac{d m}{d c_{\theta}}=f(m) \frac{d m}{d c_{\theta}}+2(1-\alpha) \int_{l}^{m}\left(\frac{v+c_{\theta}}{m+c_{\theta}}\right)^{1-2 \alpha} \frac{m+c_{\theta}-\left(v+c_{\theta}\right)\left(1+\frac{d m}{d c_{\theta}}\right)}{\left(m+c_{\theta}\right)^{2}} f(v) d v \\
& \Rightarrow\left(1-(1-\alpha) \int_{l}^{m} \frac{\left(v+c_{\theta}\right)^{2-2 \alpha}}{\left(m+c_{\theta}\right)^{3-2 \alpha}} \frac{f(v)}{f(m)} d v\right) \frac{d m}{d c_{\theta}}=(1-\alpha) \int_{l}^{m} \frac{\left(v+c_{\theta}\right)^{2-2 \alpha}(v-m)}{\left(m+c_{\theta}\right)^{2-2 \alpha}} \frac{f(v)}{f(m)} d v \\
& \therefore \frac{d m}{d c_{\theta}}<0 .
\end{aligned}
$$

Therefore, dispute incidence falls as $c_{\theta}$ increases.

Similarly, consider how dispute duration depends on $c_{\theta}$ :

$$
\begin{aligned}
& D\left(c_{\theta}\right)=1-\left(\frac{v+c_{\theta}}{m\left(c_{\theta}\right)+c_{\theta}}\right)^{1-2 \alpha} \\
& \Rightarrow \frac{d D}{d c_{\theta}}=-(1-2 \alpha)\left(\frac{m+c_{\theta}-\left(v+c_{\theta}\right)\left(1+\frac{d m}{d c_{\theta}}\right)}{\left(m+c_{\theta}\right)^{2}}\right)\left(\frac{v+c_{\theta}}{m+c_{\theta}}\right)^{-2 \alpha} \\
& \Rightarrow \frac{d D}{d c_{\theta}}=-(1-2 \alpha)\left(\frac{m-v-\left(v+c_{\theta}\right) \frac{d m}{d c_{\theta}}}{\left(m+c_{\theta}\right)^{2}}\right)\left(\frac{v+c_{\theta}}{m+c_{\theta}}\right)^{-2 \alpha} \\
& v \in[l, m] \Rightarrow(m-v) \geq 0 \\
& \therefore \frac{d D}{d c_{\theta}}<0
\end{aligned}
$$

Therefore, dispute duration falls as $\mathrm{c}_{\theta}$ increases.

Finally, we wish to show that a linear mean-preserving spread of the distribution $F$ increases both dispute incidence and dispute duration. This follows, because a linear mean-preserving spread of the distribution is equivalent to a rescaling of the original problem with a smaller $c_{\theta}$. Hence, both dispute incidence and duration increase from the calculations above.

Proof of Proposition 3. The union will select the threat that maximizes its expected payoff. Using the first order condition, yields the following equation for its expected payoff: 


$$
\begin{aligned}
U(m) & =(1-\alpha) x_{\theta}+\alpha E[v]+\frac{1}{2}\left(1-a_{\theta}\right) \\
& \times\left\{(1-2 \alpha)\left(m+c_{\theta}\right)(1-F(m))+\left(m+c_{\theta}\right)(1-F(m))-2 \alpha \int_{l}^{m} v d F(v)-2 \alpha c_{\theta} F(m)\right\} \\
& =(1-\alpha) x_{\theta}+\alpha E[v]+(1-\alpha)\left(1-a_{\theta}\right)\left(m+c_{\theta}\right)(1-F(m))-\alpha\left(1-a_{\theta}\right)\left(\int_{l}^{m} v d F(v)+c_{\theta} F(m)\right) \\
& =x_{\theta}+\left(1-a_{\theta}\right)\left(m+c_{\theta}\right)(1-F(m))+\alpha\left(-x_{\theta}+E[v]+\left(1-a_{\theta}\right)\left(\int_{l}^{m}(m-v) d F(v)-m-c_{\theta}\right)\right) \\
& =x_{\theta}+\left(1-a_{\theta}\right)\left(m+c_{\theta}\right)(1-F(m))+\alpha\left(a_{\theta} E[v]-x_{\theta}-\left(1-a_{\theta}\right) c_{\theta}+\left(1-a_{\theta}\right)\left(\int_{l}^{h} v d F(v)-m-\int_{l}^{m}(v-m) d F(v)\right)\right) \\
\therefore U_{\theta}= & x_{\theta}+\left(1-a_{\theta}\right)\left(m+c_{\theta}\right)(1-F(m))+\alpha\left(a_{\theta} E[v]-b_{\theta}+\left(1-a_{\theta}\right) \int_{m}^{h}(v-m) d F(v)\right)
\end{aligned}
$$

The union will choose strike over holdout if and only if $U_{H}<U_{S}$

$$
\begin{aligned}
& \Rightarrow w^{0}+\left(1-a_{H}\right) m_{H}\left(1-F\left(m_{H}\right)\right)+\alpha\left(a_{H} E[v]-w^{0}+\left(1-a_{H}\right) \int_{m_{H}}^{h}\left(v-m_{H}\right) d F(v)\right) \\
& <x_{S}+\left(1-a_{S}\right)\left(m_{S}+c_{S}\right)\left(1-F\left(m_{S}\right)\right)+\alpha\left(a_{S} E[v]-x_{S}+\left(1-a_{S}\right)\left(\int_{m_{S}}^{h}\left(v-m_{S}\right) d F(v)-c_{S}\right)\right) \\
& \Rightarrow(1-\alpha) w^{0}<(1-\alpha) x_{S}+\left(1-a_{S}\right)(1-\alpha)\left(m_{S}+c_{S}\right)\left(1-F\left(m_{S}\right)\right)-\alpha c_{S}\left(1-a_{S}\right) F\left(m_{S}\right) \\
& +\alpha\left(\left(a_{S}-a_{H}\right) E[v]+\left(1-a_{S}\right) \int_{m_{S}}^{h} v d F(v)-\left(1-a_{H}\right) \int_{m_{H}}^{h} v d F(v)\right)-\left(1-a_{H}\right)(1-\alpha) m_{H}\left(1-F\left(m_{H}\right)\right) \\
& \Rightarrow w^{0}<x_{S}+\left(1-a_{S}\right)\left(m_{S}+c_{S}\right)\left(1-F\left(m_{S}\right)\right)-\left(1-a_{H}\right) m_{H}\left(1-F\left(m_{H}\right)\right) \\
& -\frac{\alpha}{1-\alpha}\left(c_{S}\left(1-a_{S}\right) F\left(m_{S}\right)+\left(1-a_{S}\right) \int_{l}^{m_{S}} v d F(v)-\left(1-a_{H}\right) \int_{l}^{m_{H}} v d F(v)\right) \\
& \therefore \tilde{w}=x_{S}+\left(1-a_{S}\right)\left(m_{S}+c_{S}\right)\left(1-F\left(m_{S}\right)\right)-\left(1-a_{H}\right) m_{H}\left(1-F\left(m_{H}\right)\right) \\
& -\frac{\alpha}{1-\alpha}\left(c_{S}\left(1-a_{S}\right) F\left(m_{S}\right)+\left(1-a_{S}\right) \int_{l}^{m_{S}} v d F(v)-\left(1-a_{H}\right) \int_{l}^{m_{H}} v d F(v)\right) .
\end{aligned}
$$

Proof of Proposition 4. Under Assumption S,

$c_{\theta}=0, \forall \theta \in\{S, H\}$

$\Rightarrow m_{S}=m_{H}=m(c=0, \alpha)$ 


$$
\begin{aligned}
& \therefore D(v)=1-\left(\frac{v}{m}\right)^{1-2 \alpha} \\
& 1-F(m)=\int_{l}^{m}\left(\frac{v}{m}\right)^{2-2 \alpha} d F(v)
\end{aligned}
$$

Therefore, dispute incidence and dispute duration for a given $v$ is the same for either threat choice.

$$
\begin{aligned}
& \tilde{w}=x_{S}+\left(a_{H}-a_{S}\right)\left(m(1-F(m))-\frac{\alpha}{1-\alpha} \int_{l}^{m} v d F(v)\right) \\
& \Rightarrow \frac{d \tilde{w}}{d \alpha}=\frac{a_{H}-a_{S}}{(1-\alpha)^{2}}\left(-\int_{l}^{m} v d F(v)-\left(\alpha(1-\alpha) m f(m)-(1-\alpha)^{2}(1-F(m)-m f(m))\right) \frac{d m}{d \alpha}\right) \\
& =\frac{a_{H}-a_{S}}{(1-\alpha)^{2}}\left(-\int_{l}^{m} v d F(v)+(1-\alpha)(-m f(m)+(1-\alpha)(1-F(m))) \frac{d m}{d \alpha}\right) \\
& \frac{d m}{d \alpha}=\frac{\int_{l}^{m}\left(\frac{v}{m}\right)^{2-2 \alpha} \log \left(\frac{v}{m}\right) \frac{f(v)}{f(m)} d v}{1-(1-\alpha) \int_{l}^{m} \frac{v^{2-2 \alpha}}{m^{3-2 \alpha}} \frac{f(v)}{f(m)} d v} \\
& \Rightarrow(-m f(m)+(1-\alpha)(1-F(m))) \frac{d m}{d \alpha}=m \int_{l}^{m}\left(\frac{v}{m}\right)^{2-2 \alpha} \log \left(\frac{m}{v}\right) d F(v) \\
& \therefore \frac{d \tilde{w}}{d \alpha}=\frac{a_{H}-a_{S}}{(1-\alpha)^{2}}\left(-\int_{l}^{m} v d F(v)+(1-\alpha) m \int_{l}^{m}\left(\frac{v}{m}\right)^{2-2 \alpha} \log \left(\frac{m}{v}\right) d F(v)\right) \\
& \gamma \equiv-\int_{l}^{m} v d F(v)+(1-\alpha) m \int_{l}^{m}\left(\frac{v}{m}\right)^{2-2 \alpha} \log \left(\frac{m}{v}\right) d F(v) \\
& \therefore \gamma<-\int_{l}^{m} v d F(v)+(1-\alpha) m \int_{l}^{m}\left(\frac{v}{m}\right)^{1-2 \alpha} d F(v) \\
& v \in U[l, h] \Rightarrow \\
& \gamma<\frac{1}{h-l}\left(-\int_{l}^{m} v d v+(1-\alpha) m^{2 \alpha} \int_{l}^{m} v^{1-2 \alpha} d v\right) \\
& \Rightarrow \gamma<\frac{1}{h-l}\left(-\frac{1}{2}\left(m^{2}-l^{2}\right)+\frac{1}{2} m^{2 \alpha}\left(m^{2-2 \alpha}-l^{2-2 \alpha}\right)\right) \\
& \Rightarrow \gamma<\frac{-l^{2}}{2(h-l)}\left(\left(\frac{m}{l}\right)^{2 \alpha}-1\right) \\
& \therefore \gamma<0
\end{aligned}
$$

When $\mathrm{v}$ is distributed uniformly then holdout is used more frequently as a threat choice as $\alpha$ increases. 
$\alpha=0 \Rightarrow \gamma<-\int_{l}^{m} v d F(v)+m \int_{l}^{m} \frac{v}{m} d F(v)$
$\Rightarrow \gamma<0$

When the union is given a small positive share from zero share, then for any distribution of $v$, holdout is used more frequently as a threat choice as $\alpha$ increases. 


\section{Appendix B}

Firms that are covered with Collective Bargaining Units and that adopted ESOPs.

\begin{tabular}{lcc}
\hline $\mathbf{1 . 1}$ Company Name & Adoption Date & \% ESOP \\
\hline Anheuser-Busch Cos Inc & $4 / 27 / 1989$ & 5.5 \\
Boise Cascade Corp & $5 / 3 / 1989$ & 12.89 \\
Brunswick Corp & $4 / 4 / 1989$ & 5.97 \\
Colgate-Palmolive Co & $6 / 20 / 1989$ & 9.14 \\
Cummins Engine & $7 / 12 / 1989$ & 11.08 \\
Dennison Mfg Co & $2 / 24 / 1976$ & 5 \\
FMC Corp & $4 / 14 / 1989$ & 25.55 \\
GTE Corp & $7 / 17 / 1989$ & 3.68 \\
Lukens Inc & $6 / 29 / 1989$ & 12.8 \\
Maytag Corp & $6 / 14 / 1989$ & 3 \\
Mobil Corp & $12 / 18 / 1989$ & 2.44 \\
National Can Corp & $2 / 20 / 1985$ & 28.1 \\
National-Standard Co & $12 / 22 / 1987$ & 29.87 \\
Olin Corp & $5 / 26 / 1989$ & 6.31 \\
Phillips Petroleum Co & $6 / 16 / 1988$ & 6.12 \\
PPG Industries Inc & $1 / 20 / 1989$ & 14 \\
Quaker Oats Co & $1 / 18 / 1989$ & 2.52 \\
Rath Packing Co & $9 / 24 / 1979$ & 60 \\
Republic Airlines Inc & $7 / 3 / 1984$ & 18 \\
Sara Lee Corp & $4 / 28 / 1989$ & 6 \\
Stanley Works & $6 / 7 / 1989$ & 7.01 \\
Texaco Inc & $12 / 12 / 1988$ & 3.27 \\
Textron Inc & $6 / 8 / 1989$ & 4.17 \\
Tribune Co & $4 / 5 / 1989$ & 8.5 \\
United Technologies Corp & $7 / 3 / 1989$ & 8 \\
Us Airways Group Inc & $8 / 14 / 1989$ & 5.5 \\
Xerox Corp & $7 / 11 / 1989$ & \\
\hline
\end{tabular}

